ARTICLE

\title{
A disease-linked IncRNA mutation in RNase MRP inhibits ribosome synthesis
}

Nic Robertson', Vadim Shchepachev (1) ${ }^{2}$, David Wright ${ }^{3}$, Tomasz W. Turowski (1) ${ }^{1}$, Christos Spanos (1) ${ }^{1}$, Aleksandra Helwak', Rose Zamoyska (i) ${ }^{3} \&$ David Tollervey (i) ${ }^{1 凶}$

RMRP encodes a non-coding RNA forming the core of the RNase MRP ribonucleoprotein complex. Mutations cause Cartilage Hair Hypoplasia $(\mathrm{CHH})$, characterized by skeletal abnormalities and impaired T cell activation. Yeast RNase MRP cleaves a specific site in the pre-ribosomal RNA (pre-rRNA) during ribosome synthesis. CRISPR-mediated disruption of RMRP in human cells lines caused growth arrest, with pre-rRNA accumulation. Here, we analyzed disease-relevant primary cells, showing that mutations in RMRP impair mouse $T$ cell activation and delay pre-rRNA processing. Patient-derived human fibroblasts with $\mathrm{CHH}$ linked mutations showed similar pre-rRNA processing delay. Human cells engineered with the most common $\mathrm{CHH}$ mutation (70AG in RMRP) show specifically impaired pre-rRNA processing, resulting in reduced mature rRNA and a reduced ratio of cytosolic to mitochondrial ribosomes. Moreover, the $70^{\mathrm{AG}}$ mutation caused a reduction in intact RNase MRP complexes. Together, these results indicate that $\mathrm{CHH}$ is a ribosomopathy.

\footnotetext{
${ }^{1}$ Wellcome Centre for Cell Biology, University of Edinburgh, Edinburgh, UK. ${ }^{2}$ The Gurdon Institute and Department of Pathology, University of Cambridge Cambridge, UK. ${ }^{3}$ Ashworth Laboratories, Institute of Immunology and Infection Research, University of Edinburgh, Edinburgh, UK.

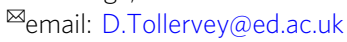


$R$ $M R P$ mutations are associated with a spectrum of disorders presenting with skeletal dysplasia, abnormal hair, and immune deficiency with impaired T-cell activation ${ }^{1}$. The most common of these syndromes is called Cartilage Hair Hypoplasia $(\mathrm{CHH})$. Patients with $\mathrm{CHH}$ have reduced life expectancy due to immune deficiency, but the mechanism underlying this problem is not understood ${ }^{1}$. Clinically, patients often experience recurrent infections, and also have a higher incidence of autoimmunity and cancer. At a cellular level, lymphocytes from $\mathrm{CHH}$ patients show reduced proliferation in response to stimulation and increased activation-induced cell death ${ }^{2,3}$. Naïve T cells are small and quiescent, but on activation increase in size over $24 \mathrm{~h}$ before beginning to rapidly divide ${ }^{4,5}$. This activation program is accompanied by a 10 -fold increase in per-cell ribosome abundance, achieved through upregulation of both ribosomal protein (RP) and ribosomal RNA (rRNA) production ${ }^{6,7}$.

Human rRNAs are transcribed by RNA polymerase I (RNAPI) as a long precursor, $47 \mathrm{~S}$ pre-rRNA (Supplementary Fig. 1). This polycistronic transcript includes the $18 \mathrm{~S}$ rRNA, destined for the small ribosomal subunit (SSU), and the $5.8 \mathrm{~S}$ and $28 \mathrm{~S}$ rRNA components of the large subunit (LSU) ${ }^{8}$. The rRNA sequences are flanked by $5^{\prime}$ and $3^{\prime}$ external transcribed spacers (5'ETS and $3^{\prime}$ ETS) and separated by internal transcribed spacers (ITS1 and ITS2). A third LSU rRNA, $5 \mathrm{~S}$, is transcribed separately by RNA polymerase III. During ribosome synthesis, the $47 \mathrm{~S}$ primary transcript undergoes a complex sequence of endonuclease cleavages and exonuclease digestion steps that remove the spacer regions. These process the $47 \mathrm{~S}$ RNA through a series of discrete pre-rRNA processing intermediates (Supplementary Fig. 1), to generate the mature rRNAs (Fig. 1A). Notably, human prerRNAs cannot be assigned to a single linear order, and there are at least two major alternative pathways. The existence of partially redundant pathways may enhance the overall efficiency and resilience of the system.

During transcription and processing, around 80 ribosomal proteins will assemble with the pre-rRNA, assisted by more than 200 protein assembly factors and over 100 small non-coding RNAs termed small nucleolar RNAs (snoRNAs) (reviewed in ref. ${ }^{9}$ ). Most snoRNAs function as guides for pre-rRNA nucleotide modification (methylation, acetylation, or pseudouridine formation) or as chaperones for pre-rRNA folding (reviewed in ${ }^{10}$ ). All known snoRNAs fall into two large families (termed boxC/D and boxH/ACA snoRNAs), with the exception of RNase MRP.

The human RMRP gene encodes a noncoding RNA, which associates with around 10 proteins in the RNase MRP complex $^{11,12}$. All of these proteins are shared with the RNase P complex, which processes pre-tRNAs and includes the evolutionarily related ncRNA RPPH $1^{9}$. RNase MRP was initially proposed to function in cleavage of an RNA primer during mouse mitochondrial DNA replication, giving its name: mitochondrial RNA processing ${ }^{12,13}$. However, in budding yeast, $\overline{\mathrm{RN}}$ ase MRP is required for cleavage at a specific site, designated A3, in the ITS1 region of the pre-rRNA. A3 cleavage provides an entry site for the $5^{\prime}$ exonuclease Rat1 (Xrn2 in humans) that then generates the $5^{\prime}$ end of the major form of $5.8 \mathrm{~S}$ rRNA ${ }^{11,14-16}$. Loss of MRP activity does not fully inhibit pre-rRNA processing due to the presence of a poorly understood alternative processing pathway. Mature $5.8 \mathrm{~S}$ rRNA is present in two different forms in all studied animals, fungi and plants ${ }^{17-19}$. In S.cerevisiae about $80 \%$ of $5.8 \mathrm{~S}$ is the short form $\left(5.8 \mathrm{~S}_{\mathrm{S}}\right)$ generated by the MRP-dependent pathway cleavage $\mathrm{e}^{14,15,17}$. The MRP-independent pathway generates $5.8 \mathrm{~S}_{\mathrm{L}}$, which is $5^{\prime}$ extended into ITS1 by 7 or 8 nucleotides. In consequence, loss of MRP activity in yeast results in a characteristic reduction in $5.8 \mathrm{~S}_{\mathrm{S}}$ relative to $5.8 \mathrm{~S}_{\mathrm{L}}$.

Previous analyses of fibroblasts from $\mathrm{CHH}$ patients showed increased abundance of species with a $5^{\prime}$ extension into ITS $1^{20}$.
By analogy with observations in yeast, this was predicted to reflect $5^{\prime}$ extension the $5.8 \mathrm{~S}$ rRNA. CRISPR-mediated disruption of RMRP in human HEK293 cells caused pre-rRNA accumulation consistent with defective ITS1 processing at "site 2" analogous to site $\mathrm{A} 3$ in yeast ${ }^{21}$. However, another analysis failed to observe an ITS1 processing defect at this site following RMRP depletion ${ }^{22}$.

Several different human diseases, collectively termed ribosomopathies, are caused by mutations or haploinsufficiency in the RNAPI transcription machinery, pre-ribosome maturation factors or ribosomal proteins (reviewed in refs. ${ }^{23-25}$ ). Despite their function in all cells, ribosomopathies are generally associated with quite cell-type specific diseases, most commonly hemopoietic defects (reviewed in refs. ${ }^{26,27}$ ). All known ribosomopathies cause only mild deficits in the accumulation of cytoplasmic ribosomes, presumably because severe defects would be lethal in early development. In consequence, tissue specificity may be caused by the combination of a generally mild deficit in translation capacity, combined with tissue-specific exacerbating factors (perhaps high demand for protein synthesis combined with reduced activity in compensating pathways).

In this study we show that mutations in $R M R P$ impair mouse T-cell activation and delay pre-rRNA processing, a phenotype recapitulated in patient-derived human fibroblasts. In cells engineered with the most common $\mathrm{CHH}$ mutation, we also observed changes in RNase MRP structure and reduction in the production of cytoplasmic ribosomes, establishing the defect as a ribosomopathy.

\section{Results}

Disruption of RMRP impairs $T$ cell proliferation and rRNA processing. Activating $\mathrm{T}$ cells require high rates of ribosome synthesis to support rapid cell division ${ }^{6}$. We hypothesized that this might confer particular vulnerability to partial disruption of $R M R P$ function if its primary biological role is in pre-rRNA processing. To test this, we used T cells from OT-1 $\mathrm{Rag}^{-/-}$mice, all of which recognize the same ovalbumin-derived antigen. This system allows $\mathrm{T}$ cells to be activated in a relatively physiological manner, by adding Ova peptide to the culture medium. Naïve primary transgenic $\mathrm{T}$ cells were isolated, stained with a division tracker dye (CellTrace Violet), and activated by culturing with ovalbumin peptide (Fig. 1a). After $24 \mathrm{~h}$, we disrupted $R M R P$ by electroporating these cells with CRISPR components, including one of four guides targeting $R M R P$, or a no-guide control (mock; Supplementary Fig. 2a). Cells were then left to proliferate for a further $48 \mathrm{~h}$.

CRISRP RNAs guide associated CAS proteins to generate sitespecific double-strand breaks in the DNA. In the absence of a repair template, these can be repaired by an error-prone nonhomologous end-joining process that generates a high frequency of nucleotide insertion and deletions (indels) at the repaired break site. Guide efficiency was therefore estimated by calculating the proportion of alleles in the population containing an indel, using the Synthego ICE tool to deconvolute Sanger sequencing traces obtained from bulk populations ${ }^{28}$. This showed that guides 1 and 2 disrupted about $60 \%$ of alleles, whereas guides 3 and 4 were less efficient, mutating approximately $20 \%$ and $10 \%$, respectively (Fig. 1b). No mutations were detected in the control. Proliferation after $48 \mathrm{~h}$ was assessed by flow cytometry using a division tracker dye, CellTrace Violet, which halves in fluorescent intensity each division (Fig. 1c,d). This showed that disruption of $R M R P$ markedly impaired T cell proliferation. Guide 1 again had the most profound effect, reducing the expansion of the culture to about $60 \%$ of that seen in mock-transfected cells. Guide 3 reduced expansion to around $70 \%$ of mock-treated cultures, while guides 2 and 4 showed a modest effect (about 80\%). Guide efficacy in this 

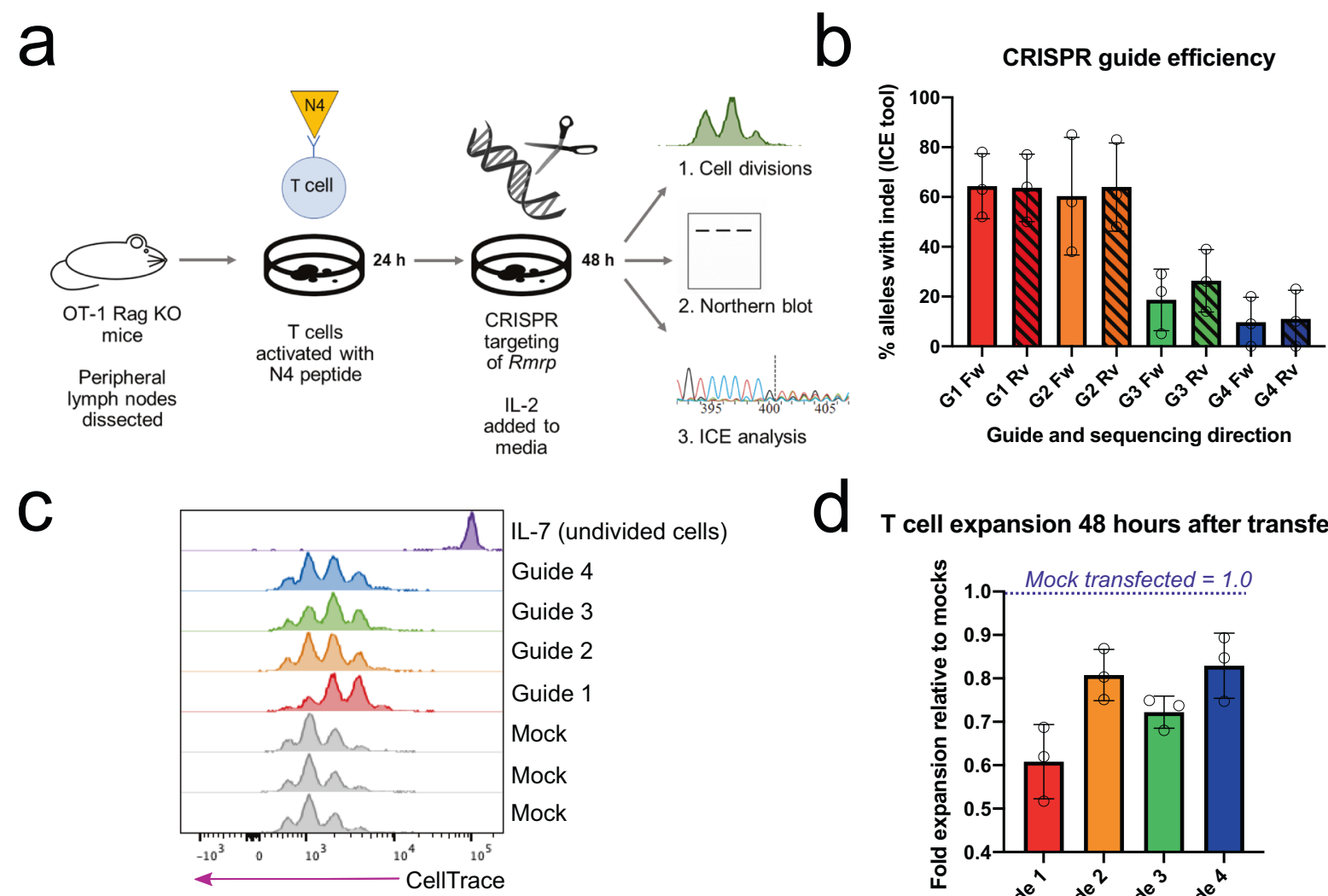

T cell expansion 48 hours after transfection
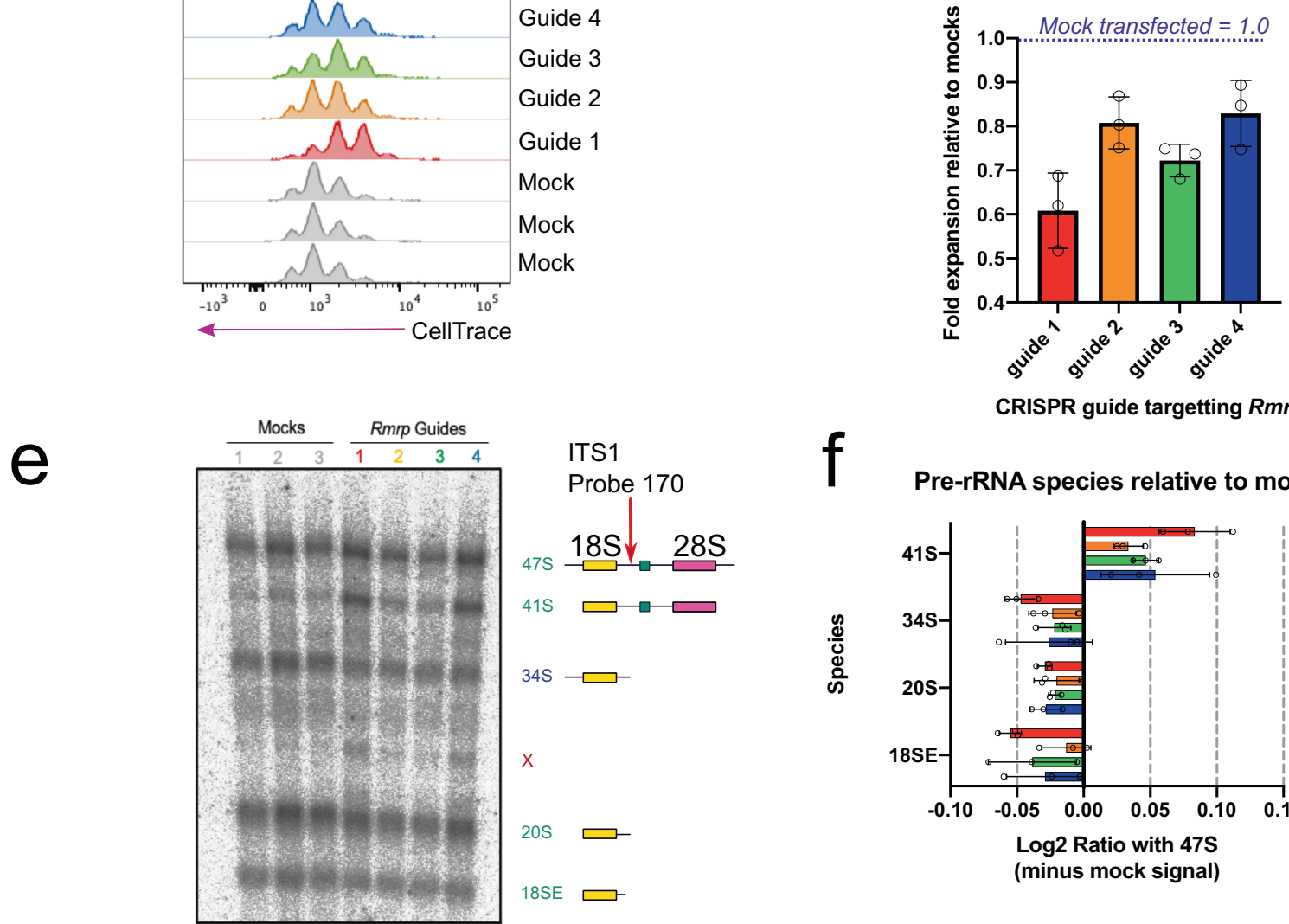

CRISPR guide targetting Rmrp

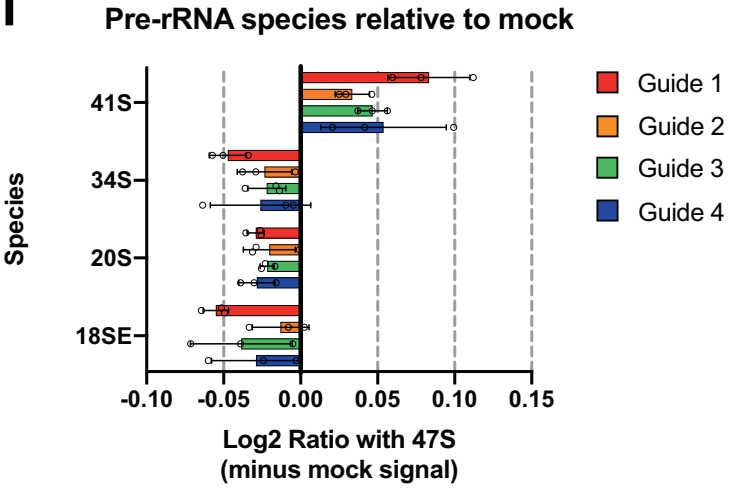

Fig. 1 Disruption of RMRP impairs T cell proliferation and rRNA processing. a Outline of experiment. Naïve TCR transgenic (OT-1) T cells were obtained from mouse peripheral lymph nodes and activated with $\mathrm{N} 4$ peptide. After $24 \mathrm{~h}$, cells were electroporated with a CRISPR mix targeting Rmrp, or a mix without the guide (mock-transfected controls). After $48 \mathrm{~h}$, cells were analyzed by flow cytometry for proliferation, northern blotting for pre-rRNA species, and ICE analysis to determine CRISPR guide efficiency. b CRISPR guide efficiency as determined by the Synthego Inference of CRISPR Edits (ICE) tool. A 669 bp region including Rmrp was amplified from DNA extracted from CRISPR-targeted cultures and sequenced with forward (Fw) and reverse (Rv) primers. The ICE tool deconvolutes Sanger sequencing traces to estimate the proportion of alleles in the population containing an indel. Graph summarizes data from three independent experiments. c T cell proliferation $48 \mathrm{~h}$ after CRISPR targeting of Rmrp, as measured with division tracker dye CellTrace Violet. Gated on live cells, as shown in Supplementary Fig. 2B. d Expansion of T cell cultures, calculated from data illustrated in panel c. Includes data from three independent experiments. In each replicate, expansion of CRISPR-targeted cultures was normalized to the average of mock-targeted controls in that experiment. e Pre-rRNA species detected by a probe in ITS1, in RNA from T cells $48 \mathrm{~h}$ after disruption of Rmrp. Cartoon on right shows species represented by each band. Pre-rRNA species indicated in green are present in both Pathway 1 and Pathway 2 (Supplementary Fig. 1). $41 \mathrm{~S}$ in brown is a Pathway 1 intermediate, and those in blue are Pathway 2 species. $\mathbf{f}$ Quantification of pre-rRNA species shown in panel $\mathbf{e}$. X indicates a noncanonical precursor; analogous bands were seen in human cells with non-specifically disrupted $R M R P^{21}$. Intensity values for each band were first normalized to the co-running $47 \mathrm{~S} / 45 \mathrm{~S}$ band in that lane. For each rRNA species, the average intensity signal from the mock controls in that experiment was then subtracted. The resulting value was Log2 transformed. Panels $\mathbf{b}$, $\mathbf{d}$, and $\mathbf{f}$ show mean values from three independent experiments, with SD. Source data are provided as a Source Data file. 
assay is predicted to depend on both guide cutting rates and the tolerance to small mutations of the target region in the RNA. These analyses were restricted to viable cells, as assessed by a dye for live/dead cells (Zombie Red), implying that non-lethal mutations in $R M R P$ slow $\mathrm{T}$ cell division.

We next assessed whether these growth defects are associated with impaired rRNA processing. RNA was extracted from cultures $48 \mathrm{~h}$ after transfection and analyzed by northern hybridization, which allows each pre-rRNA species to be visualized and quantified (Fig. 1e, left). Pre-rRNA probe 170 hybridizes in ITS $15^{\prime}$ to the site 2 , thus detecting pre-rRNAs that have not undergone cleavage at site 2 , potentially by RNase MRP (Fig. 1e, right cartoon, and Supplementary Fig. 1) ${ }^{8,29}$. For quantitation, pre-rRNAs levels were analyzed by the Ratio Analysis of Multiple Precursor (RAMP) method ${ }^{30}$, in which the abundance of each pre-rRNA species is compared to the abundance of the $47 \mathrm{~S}$ primary transcript plus the initial processing product $45 \mathrm{~S}$ pre-rRNA. These are not resolved and are jointly designated $47 \mathrm{~S}$ (Fig. 1f). All cultures treated with $R M R P$ guides showed elevated levels of $41 \mathrm{~S}$ pre-rRNA, the intermediate immediately downstream of $47 \mathrm{~S}$, whereas later intermediates were depleted. These results indicate that removal of the $5^{\prime}$ external transcribed spacer ( $5^{\prime}$ ETS) was unaffected, but cleavage in ITS1 to separate the LSU and SSU precursors is delayed (Supplementary Fig. 1).

The pre-rRNA processing defect was most prominent after targeting with guide 1 , the guide that had shown the greatest effect on proliferation and produced the largest proportion of mutated loci. However, the effect of other guides did not correlate well with their effect on proliferation. Guides 2 and 4 had similar effects on proliferation, but guide 4 caused more $41 \mathrm{~S}$ accumulation than guide 2 .

Overall, these results support the model that disruption of $R M R P$ impairs $\mathrm{T}$ cell proliferation by slowing pre-rRNA processing. However, disruption of different sites in the RMRP gene had different relative effects on cell division and pre-rRNA accumulation. We speculate that some guides preferentially cause lethal mutations in a smaller fraction of cells, while others induce milder defects in a larger population.

\section{Mutations associated with Cartilage Hair Hypoplasia impair} pre-rRNA processing. Fibroblasts from $\mathrm{CHH}$ patients have reduced growth rates and cell cycle defects ${ }^{31}$. We tested whether these problems are associated with impaired pre-rRNA processing, by measuring pre-rRNA species in patient-derived, $\mathrm{CHH}$ fibroblasts (Fig. 2a). Cells from healthy volunteers were used as controls. Being slow growing, these cells contained substantially less pre-rRNA than activated $\mathrm{T}$ cells, so obtaining high-quality RNA quantitation was challenging. Unlike $R M R P$-disrupted mouse $\mathrm{T}$ cells, the $41 \mathrm{~S}$ pre-rRNA in patient fibroblasts was not clearly increased relative to $47 \mathrm{~S}$ (Fig. 2b). $41 \mathrm{~S}$ pre-rRNA is generated in processing Pathway 1 , by initial removal of both the $5^{\prime}$ ETS and $3^{\prime}$ ETS from $47 \mathrm{~S}$, leaving the SSU and LSU rRNA precursors joined (Supplementary Fig. 1) ${ }^{29}$. In Pathway 2, initial cleavage at site 2 in ITS1 separates the $30 \mathrm{~S}$ (precursor for the SSU) and $32 \mathrm{~S}$ pre-rRNA (precursor for the LSU). Relative to $41 \mathrm{~S}$, the $30 \mathrm{~S}$ pre-rRNA was significantly less abundant in $\mathrm{CHH}$ fibroblasts than controls. We propose that slowed site 2 cleavage, caused by reduced RNase MRP activity, leads to preferential utilization of Pathway 1 over Pathway 2 in $\mathrm{CHH}$ patient cells (Fig. 2b).

To overcome the challenges of working with pre-RNA from fibroblasts, we generated a cell line homozygous for the most common $\mathrm{CHH}$-associated mutation, an $\mathrm{A}$ to $\mathrm{G}$ transition at position 71 on the current reference sequence (NBCI sequence
NR_003051.3; Supplementary Fig. 3a) ${ }^{1}$. Prior literature refers to this mutation as $70^{\mathrm{AG}}$ based on previous reference sequences, and we use $70^{\mathrm{AG}}$ for consistency. K562 cells, a suspension line derived from chronic myelogenous leukemia, were selected as the parental line $\mathrm{e}^{32}$.

The $70^{A G}$ mutation was introduced by combining CRISPR/CAS cleavage with a single-stranded repair templates including the $\mathrm{A}=>\mathrm{G}$ mutation flanked by homology arms. Position $70^{\mathrm{A}}$ overlaps a PAM site compatible with CRISPR-Cas12a (previously Cpf1), allowing the $70^{\mathrm{AG}}$ mutation to be introduced without creating extraneous mutations in the ncRNA ${ }^{33}$. Four independent, homozygous CRISPR-derived clones were obtained (Supplementary Fig. 3b). Levels of the RMRP ncRNA were not significantly reduced in these cells compared to wild-type levels, when assessed by qPCR (Supplementary Fig. 3c). For unknown reasons, one clone (clone $\mathrm{C}$ ) showed slightly reduced levels of the ncRNA RPPH1, which forms the related RNase P complex (Supplementary Fig. $3 \mathrm{c})^{12}$. All tested $70^{\mathrm{AG}}$ clones grew on average more slowly than parental cells: over $48 \mathrm{~h}$, mutant cell cultures expanded $25 \%$ less than wildtype controls (Supplementary Fig. 3d).

The cell lines gave good yields of high-quality RNA for prerRNA northern hybridization (Fig. 2c). RAMP analyses with an ITS1 probe (Probe 119; Fig. 2c left) showed that the $41 \mathrm{~S}: 47 \mathrm{~S}$ ratio was consistently increased in $70^{\mathrm{AG}}$ mutants, with an average band intensity $0.08(\log 2)$ above wildtype. In contrast, the ratios of $30 \mathrm{~S}: 47 \mathrm{~S}$ and $26 \mathrm{~S}: 47 \mathrm{~S}$ were reduced, with an average change of -0.05 and -0.06 , respectively (Fig. 2d). An ITS2 probe (Probe 123; Fig. $2 \mathrm{c}$ right), showed a visible reduction in $32 \mathrm{~S}$ relative to the $47 \mathrm{~S}$ band. Quantifying this showed that $32 \mathrm{~S}: 47 \mathrm{~S}$ was decreased by an average of -0.15 fold. To further validate these results, we used qPCR to measure the ratio of pre-rRNA ITS amplicons to $5^{\prime}$ ETS amplicons, both normalized to wildtype levels to correct for possible global perturbations of $47 \mathrm{~S}$ synthesis in these slower growing cells (Supplementary Fig. 3e, f). This showed that ITS-containing species were increased relative to the 5'ETS amplicons, consistent with an accumulation of $41 \mathrm{~S}$. Overall, we conclude that more $47 \mathrm{~S}$ is processed in Pathway 1 (via $41 \mathrm{~S}$ ) in $70^{\mathrm{AG}}$ mutants, with a decrease in Pathway 2 species (notably $30 \mathrm{~S}$ and $26 \mathrm{~S}$ ), as found in $\mathrm{CHH}$ patient cells.

In S.cerevisiae, loss of MRP activity in yeast favors accumulation of the longer $5.8 \mathrm{~S}_{\mathrm{L}}$ relative to the 6-8 nucleotide shorter form, $5.8 \mathrm{~S}_{\mathrm{s}} \mathrm{s}, 15,17$. It was previously reported that fibroblasts from $\mathrm{CHH}$ patients have perturbations in the $5.8 \mathrm{~S}$ rRNA population, with an increased abundance of species with a $5^{\prime}$ extension into ITS1, as measured by $\mathrm{qPCR}^{20}$. We assessed the ratio of $5.8 \mathrm{~S}_{\mathrm{S}}$ to $5.8 \mathrm{~S}_{\mathrm{L}}$ in the $70^{\mathrm{AG}} \mathrm{K} 562$ cells, using polyacrylamide gels for RNA separation to give nucleotidelevel resolution (Fig. 2e). In northern hybridization, $5.8 \mathrm{~S}_{\mathrm{S}}$ and $5.8 \mathrm{~S}_{\mathrm{L}}$ were clearly resolved, with $5.8 \mathrm{~S}_{\mathrm{S}}$ being more abundant. However, the $5.8 \mathrm{~S}_{\mathrm{S}}$ to $5.8 \mathrm{~S}_{\mathrm{L}}$ ratio was the same in parental and $70^{\mathrm{AG}}$ cells, at approximately 1.25 (Fig. $2 \mathrm{f}$ ). It may be that the reported, extended $5.8 \mathrm{~S}$ rRNA qPCR products were generated by accumulated pre-rRNAs, particularly $41 \mathrm{~S}$, which includes the ITS1-5.8 S region (Supplementary Fig. 1) ${ }^{20}$.

The $70^{A G}$ mutation in $R M R P$ reduces cytosolic ribosome abundance. We next assessed if the processing delay in $70^{\mathrm{AG}}$ cells resulted in a lower abundance of mature rRNA species. This is difficult to quantify using northern blotting because rRNA comprises the majority of cellular $\mathrm{RNA}^{34}$ as changes in rRNA abundance are masked when a set quantity of total RNA is loaded on the gel. Instead, we used flow cytometry to measure per-cell $18 \mathrm{~S}$ and $28 \mathrm{~S}$ RNA signals, using fluorescently-labeled oligonucleotide probes, a technique called FlowFISH (Flow-cytometry based fluorescently labelled in-situ hybridization $)^{6,35}$. Probes with 


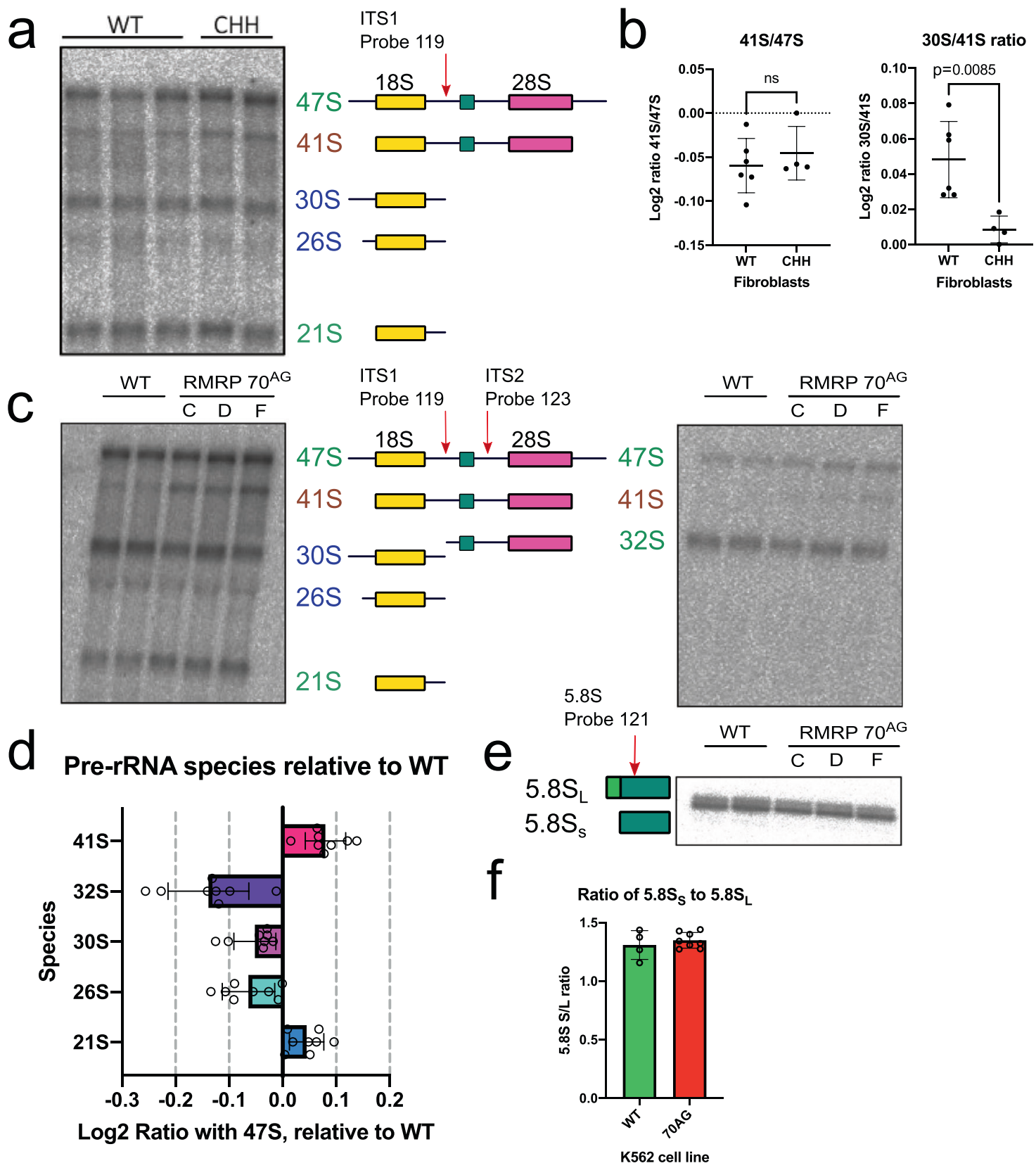

Fig. 2 Mutations associated with Cartilage Hair Hypoplasia impair rRNA processing. a Northern blot using ITS1 probe (probe 119) to detect pre-rRNA species in RNA extracted from CHH or healthy control (WT) fibroblasts. Pre-rRNA species indicated in green are present in both Pathway 1 and Pathway 2. $41 \mathrm{~S}$ in brown is a Pathway 1 intermediate, and those in blue are Pathway 2 species. b Quantification of relative abundance of $41 \mathrm{~S}$ to $47 \mathrm{~S}$, and $30 \mathrm{~S}$ to $41 \mathrm{~S}$, from northern blots as illustrated in a. Each dot represents an independent sample (total of 6 WT and 4 CHH samples; mean $+/-$ SD). Includes samples processed in two independent northern blotting experiments. Indicated $p$ value for 30/41 S derived from two-tailed $t$ test $(t=3.463, \mathrm{df}=8)$. $\mathbf{c} \mathrm{Northern}$ blot using probes against ITS1 (left; probe 119) and ITS2 (right; probe 123), to detect pre-rRNA in parental K562 cells, or CRISPR-generated clones of K562 with a $70^{A G}$ mutation in RMRP. C, D, and F represent cell lines derived from independent CRISPR clones. d Quantification of pre-rRNA species from WT and $70^{A G}$ K562 cells. The intensity of bands for each indicated species were first normalized to the $47 \mathrm{~S}$ band in that lane. Values from WT cells were then subtracted from mutant values. Includes data from three independent experiments (mean +/- SD). e Northern blot with probe against $5.8 \mathrm{~S}$ rRNA, showing the short $\left(5.8 \mathrm{~S}_{\mathrm{S}}\right.$ ) and long $\left(5.8 \mathrm{~S}_{\mathrm{L}}\right)$ form of these species in indicated cell lines. $\mathbf{f}$ Quantification of ratio between $5.8 \mathrm{~S}_{\mathrm{S}}$ and $5.8 \mathrm{~S}_{\mathrm{L}}$, determined from northern blots illustrated in $\mathbf{e}$. Includes data from three independent rounds of RNA extraction, run on two separate gels, including total of 4 wild type and 8 mutant samples (mean $+/-\mathrm{SD}$ ). Source data are provided as a Source Data file.

scrambled nucleotide sequences were used as negative controls and gave low background (Fig. 3a). All $70^{A G}$ clones tested had significantly reduced rRNA signals compared to the parental lines (Fig. 3b), but there was some variability. Clone $\mathrm{C}$ showed the greatest reduction, with an rRNA signal at about $60 \%$ of parental cells. Clone D showed approximately $80 \%$ of wildtype signal, with clone $\mathrm{F}$ at $70 \%$.
The ratio between $18 \mathrm{~S}$ and $28 \mathrm{~S}$ did not vary significantly between wild-type and mutant cells in the FlowFISH data. To support the conclusion that $18 \mathrm{~S}$ and $28 \mathrm{~S}$ rRNA were equally affected, RNA samples were run on a BioAnalyzer to quantify the relative fluorescence between mature rRNA species (Fig. 3c ${ }^{36}$. As expected, the ratio of $28 \mathrm{~S}$ to $18 \mathrm{~S}$ fluorescence was about 2 in all samples tested (reflecting the greater length of $28 \mathrm{~S}$ rRNA) 

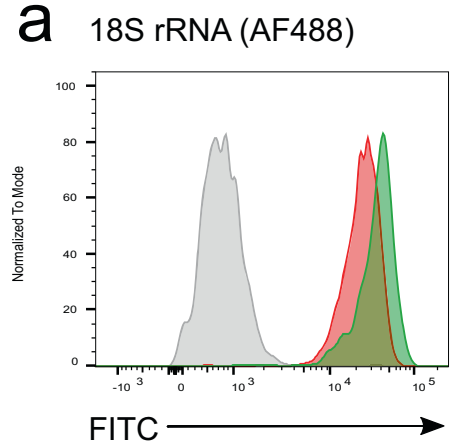

b

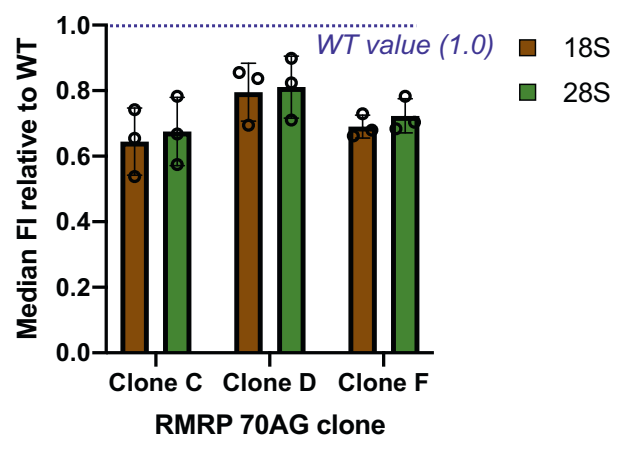

$28 \mathrm{~S}$ rRNA (AF647)

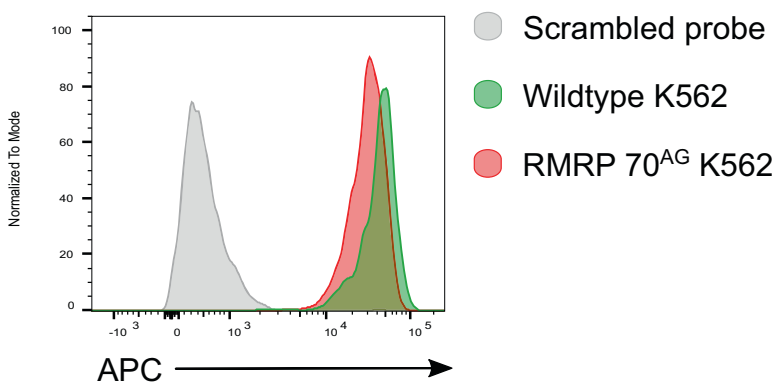

C Ratio of $28 \mathrm{~S} / 18 \mathrm{~S}$ RNA

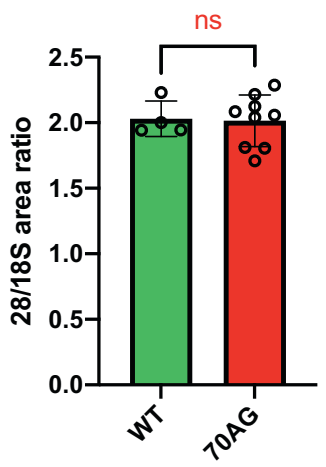

K562 cell line

Fig. 3 70 AG mutation in RMRP causes a reduction in rRNA per cell. a Example data from FlowFISH experiments, showing $18 \mathrm{~S}$ and $28 \mathrm{~S}$ rRNA detected by fluorescently-labeled antisense oligonucleotide probes, or signal from control probes with scrambled sequences. Gated on morphologically live cells. b Quantification of rRNA signals obtained in FlowFISH experiments. In each experiment, intensity values for each $70^{A G}$ clone were normalized to the signal from wild-type cells. The gating strategy is shown in Supplementary Fig. 2c. The plot shows mean of data from three independent experiments, with SD. c Ratio of $28 \mathrm{~S}$ to $18 \mathrm{~S}$ rRNA in WT and 70AG cells, as determined by BioAnalyzer analysis. Mean and SD of data obtained in three independent experiments (total of 4 WT and 9 mutant samples). Nonsignificance concluded from two-tailed unpaired $t$-test $(p=0.8963, t=0.1334, \mathrm{df}=11)$. Source data are provided as a Source Data file.

with no significant differences between the mutants and parental cells.

As per-cell rRNA was reduced in $70^{\mathrm{AG}}$ mutants, we next tested whether they also had a reduction in mature ribosomes using Total RNA-Associated Protein Purification (TRAPP) ${ }^{37}$. This method quantifies the RNA-bound proteome, with proteins recovered in proportion to their interaction with RNA. To do this, in vivo RNA:protein complexes are stabilized by UV irradiation in living cells (Fig. 4a). Cells are then lysed in denaturing conditions, and RNA-associated proteins captured by binding the RNA portion of the complex to a silica column. Unbound proteins are washed away and the remaining silica-bound RNA-associated proteins digested with trypsin. Released peptides are eluted for analysis by mass spectrometry (LC-MS-MS). Wildtype and $70^{\mathrm{AG}}$ cells were directly compared by growing each in media with isotopically-labeled "heavy" or "light" amino acids, respectively, and mixing samples 1:1 by nucleic acid content. The output of the experiment is ratios of protein abundance between mutant and wildtype cells, called SILAC ratios (Stable Isotope Labelling with Amino acids in Cell culture $)^{37,38}$. We anticipated that the $70^{\mathrm{AG}}$ mutants would show reduced relative recovery of ribosomal proteins (RPs) if mature ribosomes were less abundant in these cells.

About 1,300 SILAC ratios were recovered per mix (Fig. 4b). The mean ratio was 1 (log transformed to 0$)$, confirming that there was no systematic bias between samples (Fig. 4b). As expected, mutant cells showed a small decrease in average abundance of cytoplasmic RPs, implying reduced interaction between RPs and rRNA (Fig. 4c). Human cells have two separate populations of ribosomes, cytoplasmic and mitochondrial, which differ in both rRNA and protein composition ${ }^{39}$. The processing of mitochondrial ribosomes is independent of $R M R P$. Strikingly, recovery of cytoplasmic RPs from $70^{A G}$ cells was significantly lower than recovery of mitochondrial RPs, relative to wild-type cells (RPMs; Fig. 4c). This difference was statistically significant $(p<0.0001)$. The same result was obtained in a repeat experiment where SILAC labelling was swapped such that mutant cells were "heavy" and wild-type cells "light", confirming that it was not a technical artifact caused by SILAC labelling.

There are two possible explanations for this result. First, $70^{\mathrm{AG}}$ cells might genuinely have more mitochondrial ribosomes. RNase MRP was originally identified as cleaving an RNA primer required for mouse mitochondrial DNA replication. The $70^{\mathrm{AG}}$ mutation could potentially increase the efficiency of this process and increase mitochondrial copy number ${ }^{12}$. Alternatively, the result could be caused by normalization to total RNA. In TRAPP, equal amounts of RNA from wildtype and mutant cells are mixed in order to purify RNA-bound proteins ${ }^{37}$. If mutant cells have less total RNA per cell, due to reduced rRNA abundance, more cell-equivalents will be included in the mix relative to the wildtype. This will cause an apparent reduction in ribosomal proteins in the TRAPP-purified proteome compared to other abundant RNA-interacting proteins, such as mitochondrial RPs.

Cytoplasmic RPs are also abundant relative to the total proteome so a similar effect would be expected for analyses of 
a

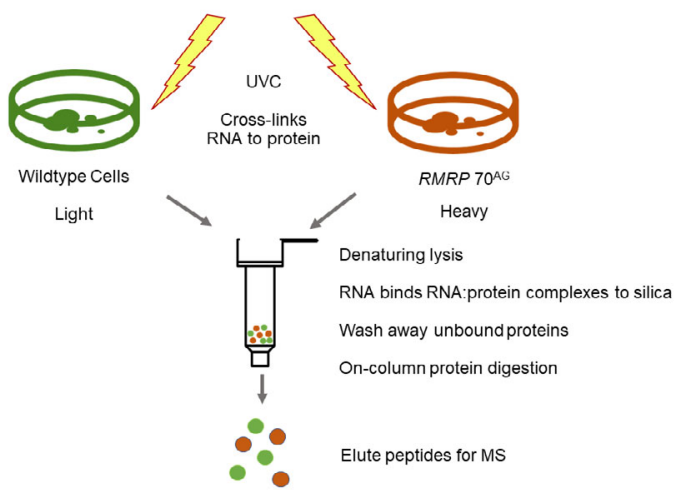

b

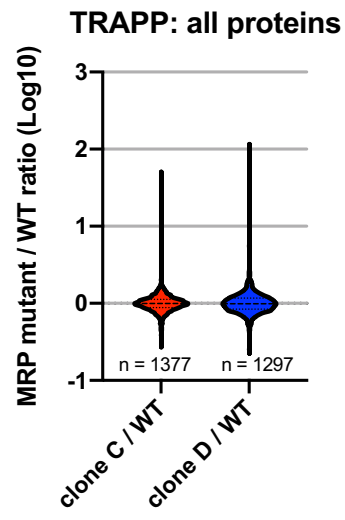

C

clone C / WT

clone D / WT

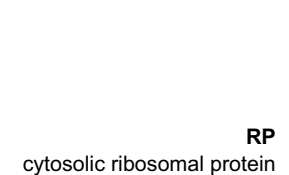

RPM

mitochondrial ribosomal protein
TRAPP: Ribosomal and mitochondrial ribosomal proteins

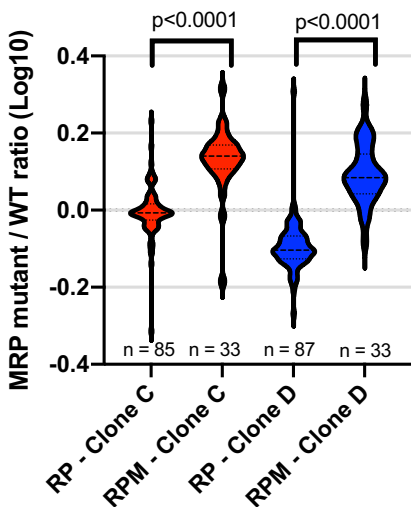

Fig. 4 70 $\mathbf{A G}$ mutation in RMRP results in a reduced ratio of cytosolic to mitochondrial ribosomes. a Overview of TRAPP technique. Wildtype and $R M R P$ $70^{A G}$ cells were grown in heavy or light SILAC media, respectively, and UV crosslinked to stabilize RNA:protein interactions. Cells were lysed in denaturing conditions, and RNA:protein complexes bound to a silica column. Nonbound proteins were washed away, and remaining proteins digested on the column. Peptides were eluted for mass spectrometry. b Log-transformed SILAC ratios (70AG mutant/wildtype) for all proteins quantified in TRAPP. $\mathbf{c}$ Logtransformed SILAC ratios for cytosolic ribosome proteins (RP) and mitochondrial ribosome proteins (RPM) obtained in TRAPP. Data shown in $\mathbf{b}$ and $\mathbf{c}$ are representative of two independent experiments, each including two SILAC mixes with different CRISPR clones. Violin plots depict distribution of SILAC ratios, with lines at median and quartiles. Indicated $p$ values derived from two-tailed $t$ tests: for clone $C, t=9.458, d f=116 ;$ for $c l o n e ~ D, t=13.62, d f=118$. Source data are provided as a Source Data file.

total protein. Indeed, the same trend was seen in SILAC total proteome data (Supplementary Fig. 4a, b).

$70^{\mathrm{AG}}$ mutation in $R M R P$ reduces the abundance of intact RNase MRP complexes. RNase MRP is a ribonucleoprotein complex comprised of the RMRP ncRNA and about 10 proteins $^{12}$. All of these are reported to be shared with an evolutionarily related ribonucleoprotein complex, RNase $\mathrm{P}$, which cleaves the $5^{\prime}$ leader from pre-tRNAs. RNase $\mathrm{P}$ includes the ncRNA RPPH1 in place of RMRP ${ }^{12}$ and has a similar abundance to $\mathrm{MRP}^{40,41}$. Mutations in the shared POP1 protein cause diseases that overlap with skeletal phenotypes of $R M R P$ mutations ${ }^{42-44}$. In recent cryo-EM structures of yeast RNase $\mathrm{MRP}^{45,46}$, Pop1 was shown to be the main structural protein in the complex. Its C-terminus interacts with the C-domain of the yeast RMRP ncRNA (called NME1), while the $\mathrm{N}$ terminal is in contact with the S-domain. No high-resolution structure of human RNase MRP has yet been reported.

In TRAPP data, POP1 and another RNase MRP/P complex protein, RPP38, showed consistently reduced RNA-association in $70^{\mathrm{AG}}$ mutants compared to controls (Fig. 5a). In analyses of total protein, POP1 was slightly less abundant in mutants than parental cells, but this was not statistically significant (SD crossing 1; Fig. 5b). The results raised the question of which
RNAs are most associated with POP1 in vivo, as these interactions must be reduced in $70^{\mathrm{AG}}$ cells to cause the reduced recovery of POP1 in TRAPP. To address this, we used the technique of crosslinking and analysis of cDNAs (CRAC; shown schematically in Supplementary Fig. 5) to map RNAs associated with individual MRP/P complex proteins ${ }^{47}$. In addition to POP1, we performed this analysis on POP4, as the yeast structures suggested this protein to be in close proximity to the known prerRNA substrate ${ }^{46}$. A CRISPR-based approach was used to insert a FLAG-HIS $_{7}$ tag onto the N or C termini of these proteins in $\mathrm{K} 562$ cells. Clones with homozygous tags were selected for analysis and RNA:protein complexes were stabilized by UV crosslinking in vivo. The bait protein was then tandem purified in stringent, denaturing conditions, and co-purifying RNAs sequenced ${ }^{47}$.

Notably, RMRP comprised the majority of RNAs recovered with POP1, making up $77-82 \%$ of sequencing reads (Fig. $5 \mathrm{c}$ ). RPPH1 was significantly less recovered with POP1, accounting for $17-23 \%$ of reads. As the abundance of RMRP was not significantly reduced in $70^{\mathrm{AG}}$ mutants (Supplementary Fig. 3c), this result indicates that the reduced total RNA interactions of POP1 in $70^{A G}$ cells likely reflects impaired POP1:RMRP interactions. POP4 CRAC recovered the opposite ratio from POP1, with $79-86 \%$ of reads representing RPPH1 (Fig. 5C). Sites of RNA:protein crosslinks in CRAC are often revealed by singlebase deletions in the sequencing data ${ }^{47}$. Mapping such crosslinks 
a TRAPP: MRP/P complex proteins

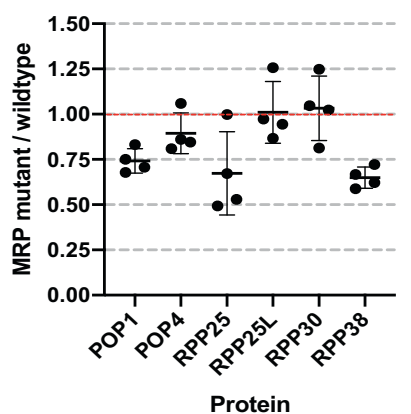

C RNA species cross-linked to MRP/P proteins

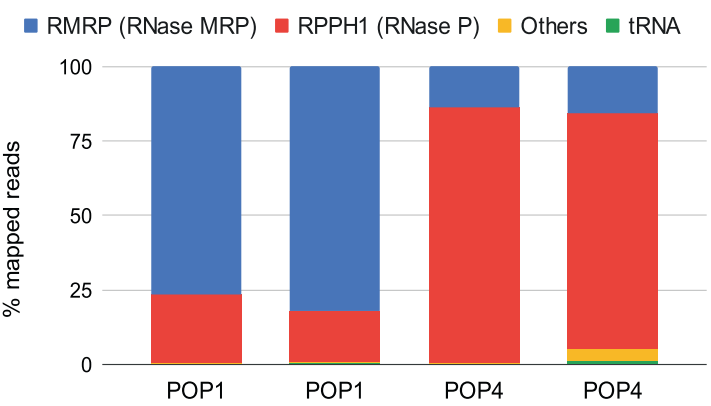

b

Proteome: POP1

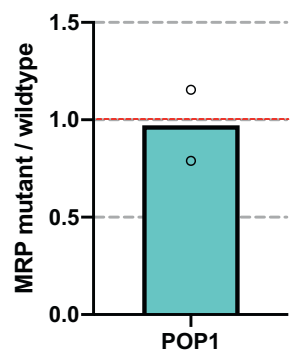

d

POP1 cross-links on RMRP

POP1 Untagged

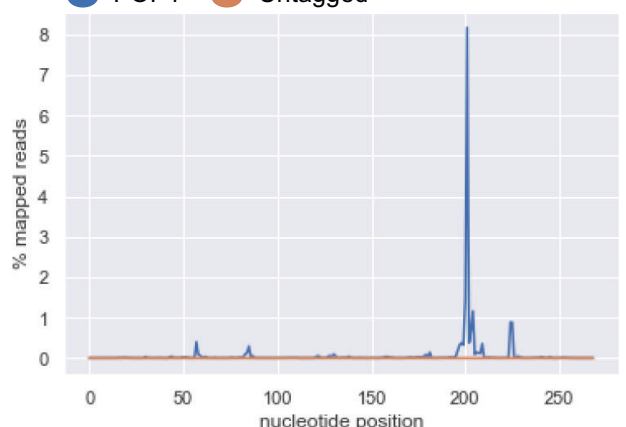

C RMRP predicted secondary structure

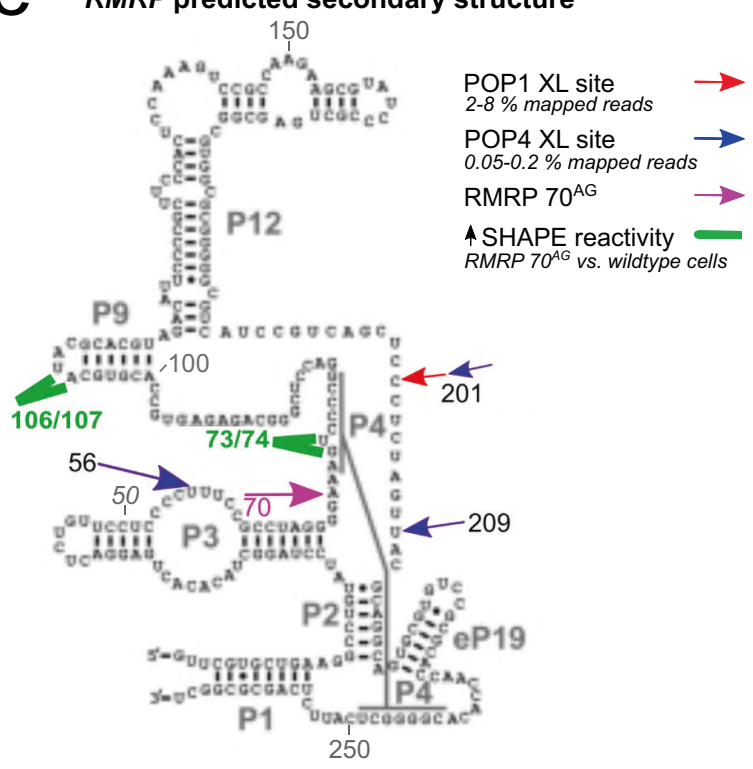

Fig. 5 70AG mutation in RMRP reduces the abundance of intact RNase MRP complexes. a SILAC ratios (70AG/wildtype cells) obtained for MRP/P complex proteins in TRAPP (mean and SD). Each dot represents data from an independent SILAC mix (total of 4 mixes, processed in 2 independent experiments). b SILAC ratios (70AG/wildtype cells) obtained for POP1 protein in proteome. Includes data from two SILAC mixes, showing mean value. c RNA species recovered from MRP/P complex proteins in CRAC. Graphs shows relative proportion of mapped reads representing each indicated RNA or RNA biotype, in two independent experiments. $\mathbf{d}$ Pileup of reads containing single base deletions (indicating RNA:protein crosslink site) in RMRP ncRNA, in POP1 or negative control CRAC. Representative of results from two independent experiments. e Possible secondary structure of RMRP, indicating sites of crosslinking with two RNase MRP complex proteins (POP1 and POP4). Nucleotides with reproducibly increased SHAPE reactivity Scores in RMRP 70AG cells are indicated. The line designated P4 indicates a predicted interaction that generates a conserved pseudoknot structure. Source data are provided as a Source Data file (panels $\mathbf{a}, \mathbf{b}$ and $\mathbf{c}$ ), and as processed data files (panel $\mathbf{d}$ ). 
across RMRP showed a clear, single site of interaction with POP1, centered on nucleotide 201 (Fig. 5d), whereas crosslinks on RPPH1 were more diffuse with several smaller peaks (Supplementary Fig. 6a, b). Conversely, POP4 CRAC showed two clear peaks in RPPH1 (at positions 122 and 186), but multiple smaller peaks for RMRP (Supplementary Fig. 6c, d). There was some overlap in the recovered crosslinking sites for POP1 and POP4. This has previously been seen for other RNPs (see for example ${ }^{48}$ ). Our interpretation is that in vivo RNPs can show flexibility, perhaps on different substrates or at different steps during their function.

To determine whether the preference for POP1 crosslinking to the RNA component of MRP over P was conserved in yeast, we tested yeast Pop1 in CRAC. This showed that, indeed, the bias was even more pronounced: $89-94 \%$ of reads were from the RNase MRP RNA (NME1 in yeast) and 3-7\% from RNase P (RPR1; Supplementary Fig. 7a). However, unlike human POP1, the yeast protein showed three distinct crosslink sites across the MRP RNA (Supplementary Fig. 7b), suggesting that the structures of human and yeast RNase MRP complexes may not be identical in vivo.

POP1 apparently shows a conserved, preferential association with RMRP ncRNA in vivo. Levels of POP1 and RMRP are maintained in $70^{\mathrm{AG}}$ cells, so the reduced POP1 recovery in TRAPP indicates that the mutation likely destabilizes the POP1:RMRP interaction. Potentially this could be associated with altered folding of the RMRP RNA in vivo. This hypothesis is supported by the finding from yeast structural data that, although human disease-causing mutations in RMRP cluster near the catalytic center of RMRP, these sites do not appear to bind the known the substrate of yeast MRP (the A3 fragment of ITS1 in pre-rRNA), implying that they may act by impairing RNA folding or complex stability.

We assessed this possibility using selective $2^{\prime}$-hydroxyl acylation analyzed by primer extension and mutational profiling (SHAPE-MaP) $^{49-51}$. In this method, an electrophilic chemical probe (1M7 in this case) is added to cultured cells and modifies RNA nucleotides in proportion to their flexibility. Sites of modification are detected as single-base mutations in sequencing data after gene-specific reverse transcription and cDNA sequencing. Overall, the obtained RMRP SHAPE reactivity profiles were similar between wildtype and $70^{\mathrm{AG}}$ cells (Supplementary Fig. 8), indicating no large-scale refolding in the mutants. Visual inspection revealed few changes, however, the deltaSHAPE tool ${ }^{50}$ performs statistical comparisons based on average reactivity at each nucleotide (Supplementary Fig. 9). This identified two areas showed small, but apparently reproducible, increases in flexibility in $70^{\mathrm{AG}}$ cells (indicated in green in Fig. $5 \mathrm{e}$ and boxed in Supplementary Fig. 9), one just downstream of the mutation (nucleotides 73 and 74) and one further $3^{\prime}$ (106 and 107).

We conclude that the disease-associated mutation likely results in subtle structural destabilization of the RNase MRP complex.

\section{Discussion}

Ribosomopathies are a diverse group of human disorders in which ribosome production or function is defective ${ }^{23-25}$. Clinical features of these disorders are variable; bone marrow dysfunction leading to anemia or cytopenia is common, as are skeletal anomalies and an increased risk of cancer. Like $\mathrm{CHH}$, many ribosomal disorders have surprisingly tissue-specific phenotypes, despite ribosomes being present in almost all cells ${ }^{26,27}$. Two broad hypotheses have been proposed to explain this. First, the phenotype may reflect decreased ribosome number or function in specific cell types that crucially depend on poorly translated mRNAs, vulnerable to reduced translation. In Diamond Blackfan anemia
(DBA), in which mutations in ribosomal proteins cause defective erythropoiesis, ribosome numbers are reduced without altered composition ${ }^{52}$. This results in reduced translation of transcripts with unstructured $5^{\prime}$ untranslated regions (UTRs), including a specific reduction in the translation of GATA2, a key hematopoietic transcription factor. Alternatively, and not mutually exclusively, some cell types may rely on specialized ribosomes, the assembly of which may be affected by particular mutations ${ }^{25}$.

Here, we present evidence that $\mathrm{CHH}$ is a ribosomopathy caused by a defect in pre-rRNA processing, Previous work reported increased levels of ITS1-containing rRNA precursors in $\mathrm{CHH}$ patient cells $\mathrm{s}^{20,53}$, but downstream effects on ribosome abundance have not previously been demonstrated. In this study, patient fibroblasts and a cell line with a disease-linked mutation ( $70^{\mathrm{AG}}$ in $\left.R M R P\right)$ showed delayed rRNA processing in a pattern consistent with decreased cleavage at the presumed RNase MRP target (site 2 in ITS1). These cells also have reduced rRNA per cell, and reduced intact cytosolic ribosomes relative to the mitochondrial ribosome pool. Moreover, the $70^{\mathrm{AG}}$ mutation reduces the abundance of intact RNase MRP complexes, probably by destabilizing the interaction between RMRP and POP1. The overall effects on ribosome synthesis are modest, but this is expected from a disease-related mutation in an essential gene, since carriers must develop almost normally in order to be classed as patients.

A high-resolution structure of the human RNase MRP complex is not currently available, and the POP1/Pop1 crosslinking sites suggest that there may be appreciable differences from the yeast structure. Based on evolutionary comparisons $s^{41,54}$, the predicted secondary structure of RMRP is shown in Fig, 5e. The line designated P4 (Fig. 5e) indicates a predicted interaction that generates a conserved pseudoknot structure. This will fold the core of the RNA into a compact 3D structure postulated to play a role in catalyzing substrate RNA cleavage. Within this structure, all indicated RNA sites will likely be in close proximity. The large POP1 protein $(115 \mathrm{kDa})$ crosslinked at a single site on RMRP (Fig. 5e). In contrast, the smaller POP4 protein $(25 \mathrm{kDa})$ crosslinked at multiple sites. Notably, one of these POP4 binding sites overlapped with one of the POP1 crosslinking sites, suggesting conformational changes within the complex, perhaps during different steps during pre-ribosome association and function. Chemical probing of structural flexibility in vivo using SHAPE-MaP ${ }^{49-51}$ did not reveal substantial changes in the mutant, although modest changes in the structure are indicated (green in Fig. 5e) at sites in the vicinity of the mutation. We speculate that changes in the overall structure of the MRP core impact negatively on the stability of protein interactions and catalytic activity in vivo.

These results advance our understanding of $\mathrm{CHH}$, but also raise some intriguing questions. Most notably, why are the phenotypes of DBA and CHH different, if reduced ribosome number is a common pathological mechanism? Some aspects of the two disorders do overlap; for example, some $\mathrm{CHH}$ patients have bone marrow dysfunction similar to that seen in $\mathrm{DBA}^{55}$. However, other aspects are unique, notably the $\mathrm{T}$ cell dysfunction which is life-limiting in $\mathrm{CHH}$ but not a feature of $\mathrm{DBA}^{1}$.

In conclusion, the results in this study point to $\mathrm{CHH}$ being a disorder of ribosome synthesis and suggest experimental approaches to further explore this complex disease.

\section{Methods}

Human cell culture. K562 cells were obtained from ATCC (cat. CCL-243), and grown in RPMI 1640 Medium with GlutaMAX Supplement (Gibco; cat. 61870036), further supplemented with 1x final concentration Antibiotic-Antimycotic (Gibco; cat. 15240096) and $10 \%$ fetal calf serum (Sigma; cat. F2442). Cells were grown to a density of $0.5-1 \times 10^{6}$ cells $/ \mathrm{mL}$, then diluted or used for experiments. 
Patient and control fibroblasts were obtained from Prof. Sophie Hambleton (Newcastle University). They were grown in DMEM with GlutaMax (Gibco; cat 10566016) supplemented with $10 \%$ fetal calf serum. Cells were grown to a confluency of $70-90 \%$ then split or used for experiments. To split, cells were washed once with sterile PBS, then incubated with $0.25 \%$ Trypsin-EDTA (Gibco; cat. $25200056 ; 0.2 \mathrm{x}$ volume of culture media removed) until detached. Trypsin was inactivated with 5 volumes of media, and cells pelleted at 100 RCF for 5 minutes before resuspension in culture media. All mammalian cell cultures were maintained at $37^{\circ} \mathrm{C}$ with $5 \% \mathrm{CO}_{2}$

Flow cytometry. Samples were prepared as described for individual methods, below. Samples were acquired on a BD LSRFortessa flow cytometer, using BD FACSDiva software, version 8.0.1. Initial data analysis was done with FlowJo version 10.6, with subsequent analysis as indicated in figure legends.

CRISPR targeting of $\boldsymbol{R} m \boldsymbol{r p}$ in primary mouse $\mathbf{T}$ cells. Rag1 KO, C57BL6/J mice were bred at the University of Edinburgh. All experimental procedures were approved by a current project license under the authority of the Animals (Scientific Procedures) Act 1986, and additionally followed the University of Edinburgh's ethical guidance as overseen by its AWERB committee.

Peripheral lymph nodes were dissected from Rag1 knockout mice homozygous for the OT1 allele. Lymph nodes were massaged through a $70 \mu \mathrm{M}$ cell strainer. Cells were washed once with IMDM (Gibco; cat. 12440053) supplemented with $2 \mathrm{mM}$ L-glutamine, counted, and resuspended at $5 \times 10^{6} \mathrm{cells} / \mathrm{mL}$ in PBS supplemented with $2.5 \mu \mathrm{M}$ CellTrace Violet (Invitrogen; cat. C34557). After $20 \mathrm{~min}$ at $37^{\circ} \mathrm{C}$, cells were washed with complete T Cell media (TCM; IMDM supplemented with $10 \%$ FCS, $2 \mathrm{mM}$ L-glutamine, $100 \mathrm{U} / \mathrm{mL}$ penicillin, $100 \mathrm{U} / \mathrm{mL}$ streptomycin, and $50 \mu \mathrm{M}$ 2-mercaptoethanol), counted, and resuspended at 250,000 cells $/ \mathrm{mL}$ in TCM supplemented with $10 \mathrm{nM} \mathrm{N} 4$ peptide (peptide sequence SIINFEKL).

After $24 \mathrm{~h}$ of stimulation, cells were counted, pelleted, and resuspended for transfection at 1.5 million cells per transfection in $80 \mu \mathrm{L}$ Neon Transfection System Buffer T (Invitrogen; cat. MPK10096). CRISPR guide RNAs were purchased from IDT (Supplementary Table 1), and resuspended at $100 \mu \mathrm{M}$ in Nuclease-Free Duplex Buffer (IDT; cat. 11-01-03-01). For each transfection, $2.5 \mu \mathrm{L}$ of guide RNA was mixed with $2.5 \mu \mathrm{L}$ of tracrRNA and $20 \mu \mathrm{L}$ of Nuclease-Free Duplex Buffer. The mix was heated at $95^{\circ} \mathrm{C}$ for $5 \mathrm{~min}$ and then allowed to cool. Once at room temperature, $23 \mu \mathrm{L}$ of Buffer T and $2 \mu \mathrm{L}$ of TrueCut Cas9 Protein v2 $(5 \mathrm{mg} / \mathrm{mL}$ stock; Invitrogen; cat A36496) was added, and the combined mix heated to $37^{\circ} \mathrm{C}$ for $10 \mathrm{~min}$ before electroporation using a Neon Transfection System with $3 \times 1600$ $\mathrm{V}$ pulses of width $10 \mathrm{~ms}$. Electroporated cells were then cultured for $48 \mathrm{~h}$ at either 250,000 (for flow cytometry) or $1 \times 10^{6}$ cells per $\mathrm{ml}$ (for northern blotting) in TCM supplemented with recombinant IL-2 $(20 \mathrm{ng} / \mathrm{mL})$. For flow cytometry, cells were first washed once with PBS before live/dead staining with Zombie Red Fixable Viability Kit (1:100 in PBS for 20 mins at room temperature; BioLegend; cat. 423109). Cells were then washed twice with FACS buffer before sample acquisition.

For proliferation experiments, fold expansion of culture was calculated by summing all the cells in this gate, and dividing this by the calculated number of initial cells. Initial cell number was calculated by first calculating the number of cells in each division peak, and dividing this by $2^{x}$, where $X$ is the number of divisions undergone by cells in that peak. Then, this value for all peaks was summed, giving the final initial cell value.

ICE analysis of CRISPR-targeted mouse T cells. 250,000 T cells were used as the input for DNA extraction, PCR and sequencing, using primers NR87 (5'-CCCACCTA GCGTTCCTACAT-3') and NR88 (5'-AGAAATAAAAGTGGCCGGGC-3'). Sanger sequencing traces were analysed using the Synthego Inference of CRISPR Edits (ICE) tool web interface 28 .

\section{Northern blotting}

RNA extraction. Mammalian cells were lysed in Trizol (Invitrogen; cat. 15596026). $200 \mu \mathrm{L}$ of chloroform was added per $1 \mathrm{~mL}$ of Trizol used for cell lysis, and the mixture incubated at room temperature for $5 \mathrm{~min}$. Phase separation, RNA precipitation, and washes were done according to manufacturer's protocol. After the wash step, the RNA pellet was resuspended in $100 \%$ formamide for northern blotting, or water for $\mathrm{qPCR}$. To ensure the RNA was fully dissolved, the mixture was left on ice for $20 \mathrm{~min}$ followed by heating at $65^{\circ} \mathrm{C}$ for $10 \mathrm{~min}$. A 1:10 dilution of RNA mix was quantified on a spectrophotometer.

Acrylamide gel for short RNA species. Loading buffer was made by supplementing $95 \%$ formamide with $20 \mathrm{mM}$ EDTA, made up with MQ. One crumb of Xylene cyanole and bromophenol blue was added per $5 \mathrm{~mL}$ of this buffer. RNA samples were mixed 1:1 with loading buffer and heated to $65^{\circ} \mathrm{C}$ for $5 \mathrm{~min}$, and then incubated on ice before loading.

Gel mix containing $8.3 \mathrm{M}$ urea was prepared by mixing $50 \mathrm{~mL}$ of $40 \%$ acrylamide gel solution (bis-acrylamide ratio 19:1; Severn Biotech; cat. 20-2400), $125 \mathrm{~g}$ of urea, and $25 \mathrm{~mL}$ of $10 \mathrm{x}$ TBE buffer, and diluting to $250 \mathrm{~mL}$ with MQ. Before pouring, $300 \mu \mathrm{L}$ of $10 \%$ ammonium persulfate and $30 \mu \mathrm{L}$ of TEMED (Sigma; cat. GE17-1312-01) were added per $50 \mathrm{~mL}$ of gel mix.
Gels were run for $1600 \mathrm{~V}$ hours (for example, $80 \mathrm{~V}$ for $20 \mathrm{~h}$ ), and samples transferred onto BrightStar-Plus Positively Charged Nylon Membrane (Invitrogen; cat. AM10100) in $0.5 \mathrm{x}$ TBE for $3 \mathrm{~h}$ at $40 \mathrm{~V}$. The membrane was then crosslinked at $254 \mathrm{nM}$ in a Statralinker cross-linking device (Stratagene).

Agarose gel for long RNA species. 50x TRI/TRI buffer was prepared by mixing $10 \mathrm{~mL}$ of triethanolamine and $13.5 \mathrm{~g}$ tricine, and bringing the volume to $50 \mathrm{~mL}$ with MQ. Agarose gel mix was prepared by combining $285 \mathrm{~mL}$ of MQ, $3 \mathrm{~g}$ of agarose and $6 \mathrm{~mL}$ of 50x TRI/TRI. Agarose was melted in a microwave and allowed to cool to just above room temperature, at which point $10.5 \mathrm{~mL}$ of $36 \%$ formaldehyde was added and the gel poured.

Gel loading dye was prepared by mixing $84 \mu \mathrm{L}$ of 50x TRI/TRI, $4 \mu \mathrm{L}$ of $0.5 \mathrm{M}$ EDTA, $80 \mu \mathrm{L}$ of $1 \%$ Bromophenol Blue and $1.84 \mathrm{~mL}$ of MQ. Pre-mix was then prepared by mixing loading dye, $36 \%$ formaldehyde, and $1 \mathrm{mg} / \mathrm{mL}$ ethidium bromide in the ratio 14:1:1. RNA samples were mixed with an equal volume of premix, and heated at $70^{\circ} \mathrm{C}$ for $10 \mathrm{~min}$, followed by cooling on ice for $5 \mathrm{~min}$ before loading. The gel was run at $140 \mathrm{~V}$ for $4.5 \mathrm{~h}$. After visualization, RNA was transferred to BrightStar-Plus Positively Charged Nylon Membrane by overnight downward capillary transfer in 10x SSC. Membranes were then crosslinked, as above.

Radioactive olionucleotide probing of northern membranes. 100x Denhardt's solution was prepared by dissolving $1 \mathrm{~g}$ of BSA fraction V, $1 \mathrm{~g}$ of Ficoll 400, and $1 \mathrm{~g}$ of PVP in $50 \mathrm{~mL}$ of MQ. Hybridization solution was prepared by combining $25 \mathrm{~mL}$ of 20x SSC, $5 \mathrm{~mL}$ of $10 \%$ SDS, and $5 \mathrm{~mL}$ of 100x Denhardt's solution, and bringing to $100 \mathrm{~mL}$ with MQ. Oligo labelling reaction mix was prepared by mixing $1 \mu \mathrm{L}$ of $10 \mathrm{mM}$ oligo with $13 \mu \mathrm{L}$ of MQ, $2 \mu \mathrm{L}$ of 10x T4 PNK Reaction Buffer (NEB; cat. B0201S), $1 \mu \mathrm{L}$ of $100 \mathrm{mM}$ DTT, $1 \mu \mathrm{L}$ of T4 PNK (NEB; cat. M0201L) and $3 \mu \mathrm{L}$ of ${ }^{32} \mathrm{P}-\gamma \mathrm{ATP}(10 \mu \mathrm{Ci} / \mu \mathrm{L}$; Hartmann Analytic). The labelling reaction was performed at $37^{\circ} \mathrm{C}$ for 1 hour. In the meantime, the membrane was pre-hybridized in hybridization solution at $50{ }^{\circ} \mathrm{C}$ with shaking. Following labelling, unincorporated ATP was removed from the reaction mix using a mini-Quick Spin Oligo Column (Roche; cat. 1814397001), following provided instructions. The recovered reaction mix was added to the membrane in $100 \mathrm{~mL}$ of hybridization solution for overnight hybridization.

The following morning, the membrane was washed four times with hybridization wash solution ( $2 \times$ SSC, $0.1 \%$ SDS). Two washes were done at room temperature, followed by a wash at $50^{\circ} \mathrm{C}$ before a final room temperature wash. Membranes were then exposed to a phosphoimager screen. Before re-hybridization with a different probe, membranes were stripped by incubating twice for $10 \mathrm{~min}$ with boiling stripping solution $(0.1 \times$ SSC, $0.1 \%$ SDS). Sequences of oligonucleotide probes used are shown in Supplementary Table 2. Acquired images were analyzed with ImageJ version 1.51 .

Generation of stable CRISPR-edited human cell lines. For all human CRISPR experiments, guide RNAs, repair templates, and check primers were ordered from IDT from the sequences in Supplementary Table 3.

Protein tagging in human cell lines. For protein tagging experiments, singlestranded templates were designed including the tag with homology arms. For POP1, a 2xFLAG-6xHIS tag was inserted at the $\mathrm{N}$ terminus. For POP4, a C terminal 8xHIS 1xFLAG tag was used, with the HIS and FLAG moieties separated by a $4 \mathrm{x}$ Ala linker.

To introduce the tags, $0.6 \mu \mathrm{L}$ of $200 \mu \mathrm{M}$ guide RNA was mixed with $0.6 \mu \mathrm{L}$ of $200 \mu \mathrm{M}$ tracrRNA (Alt-R CRISPR-Cas9 tracrRNA (IDT; cat. 1072532), heated to $95^{\circ} \mathrm{C}$ for $5 \mathrm{~min}$ then allowed to cool. Then, $2.1 \mu \mathrm{L}$ of PBS and $1.7 \mu \mathrm{L}$ of $61 \mu \mathrm{M}$ Cas9 enzyme was added (Alt-R S.p. Cas9 Nuclease V3; IDT; cat. 1081058) and the mixture incubated at room temperature for $20 \mathrm{~min}$. Meanwhile, $1 \times 10^{6}$ cells per transfection were pelleted, washed with PBS, and resuspended in $100 \mu \mathrm{L}$ of Nucleofector Solution from the Cell Line Nucleofector Kit V (Lonza; cat; VVCA-1003).

The transfection mix was assembled with $5 \mu \mathrm{L}$ of Cas9:gRNA mix (made above), $1 \mu \mathrm{L}$ of $100 \mu \mathrm{M}$ electroporation enhancer (IDT; cat.1075915), and $3 \mu \mathrm{L}$ of $10 \mu \mathrm{M}$ ssODN. Cells and transfection mix were combined and electroporated with a Lonza Nucleofector $2 \mathrm{~b}$ Device, using supplied settings for K562 cells. Cells were then gently transferred to $1.5 \mathrm{~mL}$ of K562 media supplemented with $25 \mu \mathrm{M}$ HDR Enhancer (IDT; cat. 1081072). After $48 \mathrm{~h}$, cells were sorted by FACS to 1 cell / well in a 96 well plate. Clones were screened by PCR and sequencing after about 2 weeks, using check primers shown in Supplementary Table 3.

CRISPR-Cpf1 mediated knock-in of RMRP $70^{\mathrm{AG}}$ mutation. A single-stranded repair template was designed including the mutation with homology arms. $1.6 \mu \mathrm{L}$ of $100 \mu \mathrm{M}$ Cpf1 crRNA was mixed with $1.4 \mu \mathrm{L}$ of PBS and $2 \mu \mathrm{L}$ of Cpf1 Nuclease $2 \mathrm{NLS}$ (IDT; discontinued) and incubated for $20 \mathrm{~min}$ at RT. Thereafter the procedure was the same as for CRISPR-Cas9 mediated protein tagging, except the electroporation enhancer was Cpf1-specific (IDT; cat. 1076300). 
HIS-TEV-Protein A tagging of yeast Pop1. Yeast stains in this study were derived from Saccharomyces cerevisiae strain BY4741 ${ }^{56}$. HIS-TEV-Protein A (HTP) inserts with homology arms were amplified from plasmid pBS1539 using primers listed in Supplementary Table 4 . The transformation protocol described here is adapted from Gietz and Woods ${ }^{57}$. An overnight yeast culture was diluted to $0.5 \times 10^{7}$ cells $/ \mathrm{mL}$ $(5 \mathrm{~mL}$ per transformation) and grown for 2 divisions. Cells were pelleted by centrifuging at $2000 \mathrm{~g}$ for $2 \mathrm{~min}$ at room temperature, washed with $\mathrm{MQ}$, and resuspended in transformation mix composed of $240 \mu \mathrm{L}$ PEG 3350 50\% w/v, $34 \mu \mathrm{L}$ PCR product, $50 \mu \mathrm{L}$ pre-boiled salmon sperm DNA and $36 \mu \mathrm{L} 1 \mathrm{M} \mathrm{LiAc}$.

The mix was vortexed and incubated for $40 \mathrm{~min}$ at $42^{\circ} \mathrm{C}$. Cells were then pelleted at $14,000 \mathrm{~g}$ for $30 \mathrm{~s}$ at room temperature, resuspended in $80 \mu \mathrm{L} \mathrm{MQ}$, and spread on a YPD plate. After two days, colonies were streaked onto selective medium (-URA).

qPCR. RNA was extracted from $1 \times 10^{6}$ cells, and $5 \mu \mathrm{g}$ of RNA diluted to $10 \mu \mathrm{L}$ in MQ. Reverse primer mix was made by combining $15 \mu \mathrm{L}$ of all the reverse primers listed in Supplementary Table 5, each at $100 \mu \mathrm{M}$. $2.5 \mu \mathrm{L}$ of this mix was added to each $10 \mu \mathrm{L}$ RNA sample, and the combined mix heated to $72{ }^{\circ} \mathrm{C}$ for $5 \mathrm{~min}$, after which the mix was split into two: one portion for reverse transcription and the other for a no-reverse transcription control.

Reverse transcription mix was made by combining $1.75 \mu \mathrm{L}$ of $\mathrm{MQ}, 0.75 \mu \mathrm{L}$ of $10 \mathrm{mM}$ dNTP solution, $0.1 \mu \mathrm{L}$ RNasin Ribonuclease Inhibitor (Promega; cat. N211A), $0.4 \mu \mathrm{L}$ of Superscript IV Reverse Transcriptase (Invitogen; cat 18090010) and $2 \mu \mathrm{L}$ of provided reaction buffer. Mix and RNA samples were combined, incubated at $55^{\circ} \mathrm{C}$ for 1 hour, then diluted $1: 200$ for use.

qPCR reaction mix was made by combining $2 \mu \mathrm{L}$ of cDNA or no-reverse transcription control, $0.1 \mu \mathrm{L}$ of $\mathrm{MQ}, 0.2$ each of forward and reverse primers (at $10 \mu \mathrm{M}$; Supplementary Table 5) and $2.5 \mu \mathrm{L}$ 2x SYBR Green PCR Master Mix (Applied Biosystems; cat. 4344463). Each reaction was set up in triplicate. cDNA was amplified in a LightCycler 480 (Roche), using the following cycle: initial 5 min at $95^{\circ} \mathrm{C}$, then 40 cycles of $10 \mathrm{~s}$ at $94^{\circ} \mathrm{C}, 10 \mathrm{~s}$ at $60^{\circ} \mathrm{C}$ and $15 \mathrm{~s}$ at $72^{\circ} \mathrm{C}$

$\mathrm{C}_{\mathrm{T}}$ value for each amplification curve was determined by the LightCycler software (version 1.5), and averaged for technical triplicates. Matched $\mathrm{C}_{\mathrm{T}}$ for the house-keeping gene was subtracted to give $\Delta \mathrm{C}_{\mathrm{T}}$. Fold change of mutant (Mut) cells compared to wildtype $(\mathrm{Wt})$ cells was calculated with the formula: 2 - ( $\triangle \mathrm{CT}$ Mut - $\Delta \mathrm{CT}$ $\mathrm{Wt})$. For some experiments, further analyses were undertaken, as indicated in Figure legends.

FlowfISH. The FlowFISH method ${ }^{35}$ was adapted. Probe sequences shown in Supplementary Table 6 are published ${ }^{58}$. Probes conjugated to fluorophores were ordered from IDT.

Fixation and permeabilization. $0.5 \times 10^{6} \mathrm{~K} 562$ cells were used. Cells were pelleted at $500 \mathrm{~g}$ for $5 \mathrm{~min}$ at room temperature, and washed once with $0.5 \mathrm{~mL}$ of PBS. After pelleting, cells were resuspended in $0.5 \mathrm{~mL}$ of PBS, and $0.5 \mathrm{~mL}$ of $8 \%$ paraformaldehyde added. Cells were left to fix for $30 \mathrm{~min}$ at room temperature, after which they were washed twice with $1 \mathrm{~mL}$ of PBS and resuspended in $0.5 \mathrm{~mL}$ PBS. $0.5 \mathrm{~mL}$ of $70 \%$ ethanol was then added dropwise, and cells pelleted again before resuspension in $1 \mathrm{~mL}$ of $70 \%$ ethanol and permeabilization overnight at $4{ }^{\circ} \mathrm{C}$.

Rehydration and probing. FlowFISH wash buffer (FFWB) was prepared by supplementing 2x SSC with $10 \%$ formamide and $0.25 \mathrm{mg} / \mathrm{mL}$ Bovine Serum Albumin fraction V (BSA; Sigma; cat. 05482).

FlowFISH solution A (FFSA) was prepared by combining, per sample: $5 \mu \mathrm{L}$ of formamide; $2.5 \mu \mathrm{L}$ of $2 \mathrm{x}$ SSC; $2.5 \mu \mathrm{L}$ of $10 \mathrm{mg} / \mathrm{mL}$ E. coli tRNA (Sigma; cat. R1753); $2.5 \mu \mathrm{L}$ of FISH probes diluted to $50 \mathrm{ng} / \mu \mathrm{L}$; and $8.75 \mu \mathrm{L}$ of MQ. FFSA was then heated to $95^{\circ} \mathrm{C}$ and allowed to cool. Meanwhile, FlowFISH solution B (FFSB) was prepared by combining, per sample: $25 \mu \mathrm{L}$ of $20 \%$ dextran sulphate dissolved in $4 \mathrm{x}$ SSC; $1.25 \mu \mathrm{L}$ of $10 \mathrm{mg} / \mathrm{mL}$ BSA; and 40 units of RNasin Ribonuclease Inhibitor (Promega; cat. N211A). Once FFSA was cool, FFSA and FFSB were combined 1:1 to create the staining mix.

For staining, cells in ethanol were pelleted at $1000 \mathrm{~g}$ for $5 \mathrm{~min}$, resuspended in $1 \mathrm{~mL}$ of FFWB and left to rehydrate at room temperature for $5 \mathrm{~min}$ before again being pelleted. Cells were then resuspended in staining mix for $3 \mathrm{~h}$ at $37^{\circ} \mathrm{C}$, before 2 washes with $1 \mathrm{~mL}$ FFWB, and 2 washes with $1 \mathrm{~mL}$ FACS buffer.

In-cell SHAPE-MaP. The SHAPE-MaP protocol described here is adapted from work published by the Weeks lab ${ }^{49-51,59}$. Wildtype or RMRP $70^{A G} \mathrm{~K} 562$ cells were grown to $\log$ phase, then washed with PBS and $0.8 \times 10^{6}$ cells resuspended in $900 \mu \mathrm{L}$ media. The SHAPE reagent 1M7 (Sigma; cat. 908401) was added to a final concentration of $10 \mathrm{mM}$ by adding $100 \mu \mathrm{l}$ of $100 \mathrm{mM}$ reagent resuspended in DMSO. For unmodified samples, the same volume of DMSO was added. The incell acylation reaction was left to proceed for $15 \mathrm{~min}$ at $37^{\circ} \mathrm{C}$. Cells were then pelleted, washed with PBS, and lysed in Trizol (Invitrogen; cat. 15596026). RNA was extracted using the manufacturer's phase separation protocol, and $500 \mathrm{ng}$ RNA diluted in $500 \mu \mathrm{L}$ MQ. Reverse transcription mix was made by adding $4 \mu \mathrm{L}$ of $2.5 \mathrm{mM}$ dNTP and $1 \mu \mathrm{L}$ of RMRP RT primer (5'-ACAGCCGCGCTGAGA-3') at 2 uM. The mixture was heated to $65^{\circ} \mathrm{C}$ for $5 \mathrm{~min}$, then cooled on ice.
Next, the mixture was supplemented with $4 \mu \mathrm{L}$ of $5 \mathrm{x}$ FirstStrand buffer (provided with SuperScript II; Invitrogen; cat. 18064014), $4 \mu \mathrm{L}$ of freshly prepared $30 \mathrm{mM} \mathrm{MnCl}_{2}, 2 \mu \mathrm{L}$ of $100 \mathrm{mM}$ DTT, and $1 \mu \mathrm{L}$ of RNasin Ribonuclease Inhibitor (Promega; cat. N2511), and incubated at $23^{\circ} \mathrm{C}$ for $2 \mathrm{~min} .1 \mu \mathrm{L}$ of the SuperScript II enzyme was then added. Reverse transcription was then done in a thermocycler using the following programme: $25^{\circ} \mathrm{C}$ for $10 \mathrm{~min} ; 42^{\circ} \mathrm{C}$ for $90 \mathrm{~min}$; then 10 cycles of $50{ }^{\circ} \mathrm{C}$ for $2 \mathrm{~min}$ and $42{ }^{\circ} \mathrm{C}$ for $2 \mathrm{~min}$. The enzyme was deactivated at $72{ }^{\circ} \mathrm{C}$ for $10 \mathrm{~min}$. Buffer components and the RT primer were removed by purifying the cDNA mixture using a mini-Quick Spin Oligo Column (Roche; cat. 1814397001), eluting with $15 \mu \mathrm{L} \mathrm{MQ}$.

To prepare a sequencing library, two sequential PCRs were performed. First, $5 \mu \mathrm{L}$ of the purified cDNA was amplified using the primers NRs2-MRP-PCR1-FW and NRs3-MRP-PCR1-RW (Supplementary Table 7, adapted from ${ }^{60}$ ), in a $50 \mu \mathrm{L}$ reaction mix containing $10 \mu \mathrm{L}$ of 5x Q5 buffer (provided with Q5 polymerase kit; NEB; cat. M0491L), $4 \mu \mathrm{L}$ of $2.5 \mathrm{mM} \mathrm{dNTP}, 2.5 \mu \mathrm{L}$ of each primer at $10 \mu \mathrm{M}$, and $0.5 \mu \mathrm{L}$ of the $\mathrm{Q} 5$ polymerase. The reaction was performed using the following program: initial denaturation at $98^{\circ} \mathrm{C}$ for $10 \mathrm{~s}$, then 30 cycles of $98^{\circ} \mathrm{C}$ for $10 \mathrm{~s}$, annealing at $60^{\circ} \mathrm{C}$ for $30 \mathrm{~s}$ and extension at $72^{\circ} \mathrm{C}$ for $20 \mathrm{~s}$. The final extension was at $72^{\circ} \mathrm{C}$ for $2 \mathrm{~min}$. The reaction was purified using AMPure XPbeads, as described in the Library Preparation subsection of "CRAC protocol for human cell samples", below.

$1 \mathrm{ng}$ of this purified product was used as the input template for the second PCR, assembled essentially as before. Primers for this reaction were NRs4-PCR2-RW, and one of the barcoded universal SHAPE forward primers from Supplementary Table 7 . The annealing temperature for this second reaction was $66^{\circ} \mathrm{C}$. The final libraries were gel purified, diluted to $2 \mathrm{ng} / \mu \mathrm{L}$ and pooled. Libraries were sequenced on an Illumina NextSeq 550 instrument using a mid-output flow cell (2×150 reads).

SHAPE reactivity profiles and comparisons were generated using the ShapeMapper 2 and deltaSHAPE scripts, using default settings and aligning to $R M R P$. Mutant samples were aligned to a modified $R M R P$ reference sequence containing the $70^{\mathrm{AG}}$ mutation, to prevent the detection of spuriously high mutation rates at this site ${ }^{49,50}$.

Total RNA-associated protein purification (TRAPP). K562 were grown for 10 divisions in SILAC RPMI (Thermo Fischer; cat. 88365) supplemented with $10 \%$ dialyzed FBS (Gibco; cat. 26400044) and $50 \mu \mathrm{g} / \mathrm{L}$ each of lysine and arginine. For "light" cultures, these amino acids were obtained from Sigma. For "heavy" cultures, ${ }^{13} \mathrm{C}_{6}$-lysine and ${ }^{13} \mathrm{C}_{6}$-arginine were obtained from Cambridge Isotope Laboratories (cat. CLM-226 and CLM-2247, respectively).

Cells were grown to a density of $0.5-0.8 \times 10^{6}$ cells $/ \mathrm{mL}$, with minimum $90 \%$ viability as determined by Trypan blue exclusion (Invitrogen; cat. T10282) using a Countess automated cell counter. $25 \mathrm{~mL}$ aliquots of culture were transferred to a custom quartz dish, and crosslinked with $400 \mathrm{~mJ} / \mathrm{cm}^{2}$ of UVC using a Vari-X-Link device ${ }^{61}$. Enough aliquots were crosslinked to create a sample containing $50 \times 10^{6}$ cells. After cross-linking, cells were pelleted, washed with ice-cold PBS, and frozen at $-80{ }^{\circ} \mathrm{C}$.

RNA-associated proteins were purified following a modified version of the published TRAPP protocol, where silica columns were used in place of silica beads $^{37}$. Proteins were digested on the column with $0.25 \mu \mathrm{g}$ of Trypsin/Lys-C protease mix (Promega; cat. V5071), and peptides eluted for mass spectrometry. Samples were acquired by the Proteomics Facility at the Wellcome Centre for Cell Biology, University of Edinburgh, on an Orbitrap Fusion Lumos Tribrid Mass Spectrometer (Thermo Fisher Scientific, UK). Raw data were processed by the MaxQuant software platform, version 1.6.1, searching against the UniProt reference proteome set. Further analysis used custom scripts. A paper describing this modified TRAPP protocol is in preparation.

Proteomics. Cells were lysed in 1x Laemmli buffer, quantified, and boiled for $5 \mathrm{~min} .20 \mu \mathrm{g}$ of protein was run per lane on a $12 \%$ pre-cast gel (BioRad; cat 4561043), with size determined using a pre-stained protein ladder run in lane 1 (NEB; cat. P7719S). The gel was washed three times with MQ, each for $5 \mathrm{~min}$ with nutation, then stained with Imperial protein stain (Thermo Scientific; cat. 24615) for 1 hour, and destained with MQ overnight. The gel was cut into fractions, and each fraction dissected into cubes not more than $1 \mathrm{~mm}^{3}$ in volume. Proteins were then digested with trypsin and StageTips created, following a published protocol ${ }^{62}$ Samples were acquired and analyzed as described for TRAPP.

\section{Cross-linking and analysis of cDNAs (CRAC)}

Preparation of human CRAC samples. Cells were grown and crosslinked as for TRAPP, except that normal RPMI media was used rather than SILAC media.

Preparation of samples for yeast Pop1 CRAC. $2.75 \mathrm{~L}$ of yeast culture was grown to $0.5 \mathrm{OD}$, and irradiated for $100 \mathrm{~s}$ with UVC $(254 \mathrm{nM})$ in a custom "Megatron" cross-linking device, as described ${ }^{47}$. Cells were then pelleted $(2700 \mathrm{RCF}$ for $15 \mathrm{~min}$ at $4{ }^{\circ} \mathrm{C}$ ) and washed with ice-cold PBS, pelleted again, and frozen at $-80^{\circ} \mathrm{C}$ until use. 
CRAC protocol. For yeast Pop1, CRAC was performed following a published protocol $^{63}$. For human CRAC, technical modifications were made to this protocol. The full human CRAC protocol is described below.

Sequencing and analysis of CRAC data. CRAC libraries were sequenced either on a MiniSeq or HiSeq, both with 150 base reads. Yeast CRAC data were processed using custom scripts calling utilities from the PyCRAC collection ${ }^{64}$. First, raw FASTQ files were demultiplexed using pyBarcodeFilter. Then, adapters and lowquality sequences were removed with Flexbar (version. 3.4.0) ${ }^{65}$. Next, PCR duplicates were collapsed with pyFastqDuplicateRemover. Reads were then aligned to the Saccharomyces cerevisiae genome sequence from Ensembl release EF4.74 [ftp://ftp.ensembl.org/pub/release-74/gtf/saccharomyces_cerevisiae] by Novoalign version 2.07.00. Read counts were produced using pyReadCounters, and pileups with pyPileup. Graphs were produced with custom Python3 scripts, available on request. For human data, low-quality reads were removed with Flexbar. STAR (version. 2.7.3a) was then used to align reads to a custom transcriptome database, based on GRCh38.p13 [https://www.ncbi.nlm.nih.gov/assembly/ GCF_000001405.39] with additional tRNA and rRNA species included. Read counts and pileups were generated with custom scripts, available on request.

CRAC protocol for human cell samples. Buffers were prepared as in Supplementary Table 8. Crosslinked cell pellets were resuspended in $3 \mathrm{~mL}$ of ice-cold buffer LB, supplemented with cOmplete EDTA-free Protease Inhibitor Cocktail (Roche; cat. 11873580001; 1 tablet per $50 \mathrm{~mL}$ lysis buffer), and left to lyse for $10 \mathrm{~min}$ on ice. To ensure complete lysis, $0.5 \mathrm{~mL}$ of zirconium oxide beads (Thistle Scientific; cat. ZrOB05) were then added and the samples vortexed for $30 \mathrm{~s}$. Samples were then centrifuged at $1000 \mathrm{~g}$ for $5 \mathrm{~min}$ at $4{ }^{\circ} \mathrm{C}$, and the supernatant clarified by syringe-filtration through a $0.22 \mu \mathrm{M}$ filter.

anti-FLAG IP. $100 \mu \mathrm{L}$ of anti-FLAG M2 magnetic beads (Milipore; cat. M8823) were washed twice with $0.5 \mathrm{~mL}$ of buffer $\mathrm{LB}$, then added to the sample and nutated at $4{ }^{\circ} \mathrm{C}$ for $2 \mathrm{~h}$. Using a magnetic rack, beads were then washed three times with $1 \mathrm{~mL}$ buffer $\mathrm{LB}$ and twice with $1 \mathrm{~mL}$ buffer $\mathrm{C}$, then resuspended in $300 \mu \mathrm{L}$ of buffer $\mathrm{C}$.

Partial RNA digestion. RNA was partially digested by adding $300 \mu \mathrm{L}$ of Buffer C supplemented with 0.04 units of RNace-IT (Agilent; cat. 400720) and incubating at $23^{\circ} \mathrm{C}$ for 10 min with shaking (100 RPM). Beads were then washed once with $0.75 \mathrm{~mL}$ of buffer LB, once with $0.75 \mathrm{~mL}$ of buffer FA2 (3 min on ice with nutation), once with $0.75 \mathrm{~mL}$ of buffer FA3 (again, on ice with nutation), and, finally, twice with $0.75 \mathrm{~mL}$ of buffer $\mathrm{LB}$.

Elution from FLAG beads. Buffer was removed from the beads using a magnetic rack. The beads were then resuspended in $200 \mu \mathrm{L}$ of buffer LB supplemented with $150 \mu \mathrm{g} / \mathrm{mL}$ of 3x FLAG peptide (Sigma; cat. F4799) and incubated for $5 \mathrm{~min}$ at $37^{\circ} \mathrm{C}$, shaking at $1200 \mathrm{RPM}$. The eluate was collected and the elution repeated. The two eluates were pooled and $800 \mu \mathrm{L}$ of buffer WB1 added to denature proteins.

HIS-tag purification. $75 \mu \mathrm{L}$ of nickel beads (Ni-NTA Aragose; Qiagen; cat. 30210) were washed twice with $1 \mathrm{~mL}$ of buffer WB1, spinning at 1000 RCF for 30 seconds and removing supernatant between washes. Eluate was added to the beads and incubated for $2 \mathrm{~h}$ at RT with nutation. Beads were then washed as before, three times with $1 \mathrm{~mL}$ of buffer WB1 and twice with $0.75 \mathrm{~mL}$ of buffer C. After the last wash, beads were resuspended in $600 \mu \mathrm{L}$ of buffer $\mathrm{C}$ and transferred to a SigmaPrep column (Sigma; cat. SC1000).

RNA dephosphorylation. Beads on the column were washed twice with $0.75 \mathrm{~mL}$ of $50 \mathrm{mM}$ Bis-Tris pH 6.5. For this and all column steps, buffer was allowed to pass through the column using gravity flow. Dephosphorylation was then initiated by adding $80 \mu \mathrm{L}$ of reaction mix containing $4 \mu \mathrm{L}$ of T4 Polynucleotide Kinase (NEB; cat. M0201L), $2 \mu \mathrm{L}$ of TSAP Thermosensitive Alkaline Phosphatase (Promega; cat. M9910) and $2 \mu \mathrm{L}$ of RNasin Ribonuclease Inhibitor (Promega; cat. N2511), in 1x $\mathrm{R} 2$ buffer (diluted from 10x stock with MQ). Samples were incubated for $30 \mathrm{~min}$ at $37^{\circ} \mathrm{C}$, and then the columns were washed once with $0.5 \mathrm{~mL}$ of buffer $\mathrm{WB} 1$ and three times with $0.75 \mathrm{~mL}$ of buffer $\mathrm{C}$.

$3^{\prime}$ Linker ligation. To facilitate cloning, a DNA linker was ligated to the $3^{\prime}$ of the RNA. This linker was synthesised by IDT. It has a blocked $3^{\prime}$ end and an activated adenosine at the $5^{\prime}$ end, with sequence: $5^{\prime}$-rAppTGGAATTCTCGGGTGCCAA GG/ddC/ $-3^{\prime}$. Ligation was initiated by adding $80 \mu \mathrm{L}$ of reaction mix containing $8 \mu \mathrm{L}$ of $10 \mu \mathrm{M}$ linker, $4 \mu \mathrm{L}$ of truncated T4 RNA ligase II (NEB; cat. M0373L), $2 \mu \mathrm{L}$ of RNasin and $20 \mu \mathrm{L}$ of $50 \%$ PEG8000, in 1x R1 buffer. The reaction was left to proceed overnight at $16^{\circ} \mathrm{C}$. The next morning, columns were washed once with $0.5 \mathrm{~mL}$ of buffer WB1, once with $0.75 \mathrm{~mL}$ of buffer B2, once with $0.5 \mathrm{~mL}$ of buffer B3, once with $0.75 \mathrm{~mL}$ of buffer $\mathrm{B} 2$, and, finally, three times with $0.75 \mathrm{~mL}$ of buffer C.

RNA labelling, $5^{\prime}$ linker ligation and elution. RNA was radioactively labelled by adding $80 \mu \mathrm{L}$ of reaction mix containing $4 \mu \mathrm{L}$ of ${ }^{32} \mathrm{P}-\gamma \mathrm{ATP}(10 \mu \mathrm{Ci} / \mu \mathrm{L}$; Hartmann
Analytic), $2 \mu \mathrm{L}$ of T4 Polynucleotide Kinase, $2 \mu \mathrm{L}$ of RNasin and $20 \mu \mathrm{L}$ of $50 \%$ PEG8000, in 1x R1 buffer. After $30 \mathrm{~min}$ at $37^{\circ} \mathrm{C}, 1 \mu \mathrm{L}$ of $100 \mathrm{mM}$ ATP (ThermoFisher; cat. 10304340) was added, and the reaction left for an additional $15 \mathrm{~min}$. A $5^{\prime}$ linker was then ligated by adding $4 \mu \mathrm{L}$ of T4 RNA ligase 1 (NEB; cat. M0204L) and $4 \mu \mathrm{L}$ of $100 \mu \mathrm{M}$ barcoded linker. The reaction was performed for $3 \mathrm{~h}$ at $16^{\circ} \mathrm{C}$ then $2 \mathrm{~h}$ at $25^{\circ} \mathrm{C}$ The $5^{\prime}$ linker was again produced by IDT. It has an inverted ddT at the $5^{\prime}$ end to increase stability and a barcode sequence at the $3^{\prime}$ end. Also at the $3^{\prime}$ end, there is a random 3-mer to allow collapsing of PCR duplicates. Following ligation, columns were washed three times with $0.5 \mathrm{~mL}$ of buffer WB1. RNA:protein complexes were then eluted by incubating beads with $50 \mu \mathrm{L}$ of buffer BE ( 5 min at RT, shaking at $800 \mathrm{RPM}$ ), then spinning out eluate (1000 RCF for $1 \mathrm{~min}$ at RT). Elution was repeated, and eluates combined. RNA:protein complexes were then precipitated by adding 9 volumes of $100 \%$ ethanol and $3 \mu \mathrm{L}$ of GlycoBlue co-precipitant (Invitrogen; cat. AM9516), and incubating samples overnight at $-20^{\circ} \mathrm{C}$.

Size selection of RNA:protein complexes. The next morning, samples were centrifuged at $21,000 \mathrm{RCF}$ for $20 \mathrm{~min}$ at $4{ }^{\circ} \mathrm{C}$ and the supernatant removed. Pellets were washed twice with $1 \mathrm{~mL}$ of $80 \%$ acetone, then allowed to dry. Pellets were then resuspended in $12 \mu \mathrm{L}$ of MQ and left to rehydrate for 10 min at RT. $4 \mu \mathrm{Lof} 4 \mathrm{x}$ NuPage LDS sample buffer (Invitrogen; cat. NP0007) was added, together with 2-Mercaptoethanol to a final concentration of $2 \%$.

Samples were then denatured at $65^{\circ} \mathrm{C}$ for $10 \mathrm{~min}$, and loaded onto a NuPage 4$12 \%$ polyacrylamide gel (Invitrogen; cat. NP0321). The gel was run at $120 \mathrm{~V}$ in 1xNuPAGE MOPS SDS Running Buffer (Invitrogen; cat. NP0001), then transferred onto Hybond-CExtra membrane (Fischer Scientific; cat. 10564755) in 1x NuPAGE transfer buffer (Invitrogen;cat. NP0006) supplemented with $10 \%$ methanol, for $2 \mathrm{~h}$ at $100 \mathrm{~V}$.

Membranes were then exposed overnight to Kodak BioMax MS autoradiography film (Sigma;cat. K8222648). Using the radiograph as a guide, areas corresponding to RNA libraries were cut from the membrane, and proteins digested in buffer PKB supplemented with $100 \mu \mathrm{g}$ of proteinase K (Sigma; cat. $3115887001)$ for 1 hour at $55^{\circ} \mathrm{C}$ with shaking (1400 RPM). RNA was then extracted by adding $50 \mu \mathrm{L}$ of $3 \mathrm{M} \mathrm{NaAC}$ and $50 \mu \mathrm{L}$ of buffer PCI, centrifuging at 20,000 RCF for $5 \mathrm{~min}$ at $4{ }^{\circ} \mathrm{C}$, and taking the upper phase into a new tube. RNA was then precipitated by adding $1 \mathrm{~mL}$ of $100 \%$ ethanol and $2 \mu \mathrm{L}$ of GlycoBlue, and incubating overnight at $-20^{\circ} \mathrm{C}$.

Reverse transcription. The following morning, samples were centrifuged at 21,000 RCF $\left(4^{\circ} \mathrm{C}\right.$ for $\left.20 \mathrm{~min}\right)$. The supernatant was removed and pellets washed with $70 \%$ ethanol, before being allowed to dry. The pellet was resuspended in $11 \mu \mathrm{L}$ of MQ supplemented with $1 \mu \mathrm{L}$ of $10 \mu \mathrm{M}$ miRCat RT oligo (sequence: CCTTGGCACCC GAGAATT) and $2.5 \mu \mathrm{L}$ of $2.5 \mathrm{mM}$ dNTP mix (diluted from $100 \mathrm{mM}$ stocks: Invitrogen; cat. 10297117). The mix was heated to $80^{\circ} \mathrm{C}$ for 3 min then chilled on ice for $5 \mathrm{~min} .6 \mu \mathrm{L}$ of RT mix was then added, composed of $4 \mu \mathrm{L}$ SuperScript IV RT Reaction Buffer (Invitrogen;cat 18090050B), $1 \mu \mathrm{L}$ of $100 \mathrm{mM}$ DTT and $1 \mu \mathrm{L}$ RNasin. The mix was heated to $50^{\circ} \mathrm{C}$ for $5 \mathrm{~min}$, then $1 \mu \mathrm{L}$ of Superscript IV reverse transcriptase (Invitrogen; cat 18090010) was added and the reaction left for $15 \mathrm{~min}$. The mixture was then incubated at RT for $5 \mathrm{~min}$, then on ice for $3 \mathrm{~min}$. $2 \mu \mathrm{L}$ of Exonuclease I (NEB; cat. M0293S) was then added and the mixture incubated for $30 \mathrm{~min}$ at $37^{\circ} \mathrm{C}$, before heating to $80^{\circ} \mathrm{C}$ for $20 \mathrm{~min}$ to deactivate the enzyme.

Library preparation. DNA libraries were amplified using the primers P5 Forward (AATGATACGGCGACCACCGAGATCTACACTCTTTCCCTACACGACGCTC TTCCGATCT) and PE miRCat Reverse (CAAGCAGAAGACGGCATACGAG ATCGGTCTCGGCATTCCTGGCCTTGGCACCCGAGAATTCC). PCR reactions were assembled in $50 \mu \mathrm{L}$ and contained $0.3 \mu \mathrm{L}$ of Phusion High-Fidelity DNA Polymerase (NEB; cat. M0530S), $10 \mu \mathrm{L}$ of provided $5 \mathrm{x}$ Phusion buffer, $5 \mu \mathrm{L}$ of $2.5 \mathrm{mM}$ dNTP mix, $1 \mu \mathrm{L}$ of each primer, and $2 \mu \mathrm{L}$ of cDNA. cDNA was amplified using the following programme: initial denaturation at $98^{\circ} \mathrm{C}$ for $30 \mathrm{~s}$, then 18 to 22 cycles of $98^{\circ} \mathrm{C}$ for $10 \mathrm{~s}, 65^{\circ} \mathrm{C}$ for $30 \mathrm{~s}$ and $72^{\circ} \mathrm{C}$ for $30 \mathrm{~s}$. The final extension was at $72^{\circ} \mathrm{C}$ for $5 \mathrm{~min}$. Three reactions were completed for each sample. Once complete, the PCR reactions were pooled for each sample and purified using AMPure XPbeads (Beckman Coulter; cat. A63880). Per reaction mix, 2 volumes of AMPure buffer and 0.2 volumes of AMPure XP beads were added. Samples were mixed and incubated for $5 \mathrm{~min}$ at RT. The supernatant was then removed on a magnetic rack and beads washed twice with $200 \mu \mathrm{L}$ of $80 \%$ ethanol. After the last wash, ethanol was removed and the beads left to dry.

Purified DNA was then eluted by resuspending the beads in $10 \mu \mathrm{L}$ of $\mathrm{MQ}$, and $2 \mu \mathrm{L}$ of 6x DNA gel loading dye added (Thermo Scientific; cat. R0611). A 3\% Metaphor agarose (Lonza; cat. 50181) gel was prepared in 1x TBE. Samples were loaded and run at $80 \mathrm{~V}$ until dye reached the bottom of the gel. The smear corresponding to the DNA library was extracted with a Zymoclean Gel DNA Recovery Kit (Zymo; cat. D4007), and fluorometrically quantified. Libraries were diluted to approximately $5 \mathrm{nM}$ and pooled, and submitted for sequencing on an Illumina HiSeq2500 platform at the Wellcome Trust Clinical Research Facility, University of Edinburgh.

Statistics. All statistics were calculated using Prism 9.0.0, with tests as indicated in figure legends. In general, plots show mean values $+/-$ standard deviations. 
Reporting Summary. Further information on research design is available in the Nature Research Reporting Summary linked to this article.

\section{Data availability}

The data that support this study are available from the corresponding author upon reasonable request. The GEO accession number for all sequence data reported in this paper is GSE171021. The proteomics data are available through the ProteomeXchange partner repository with the dataset identifier PXD025029. Human reference sequences used in this paper were taken from GRCh38.p13 [https://www.ncbi.nlm.nih.gov/ assembly/GCF_000001405.39]. Yeast sequences are from the Saccharomyces cerevisiae genome (Ensembl release EF4.74 [ftp://ftp.ensembl.org/pub/release-74/gtf/ saccharomyces_cerevisiae]). Mouse sequences are from GRCm39 [https:// www.ncbi.nlm.nih.gov/assembly/GCF_000001635.27/]. Source data are provided with this paper.

Received: 3 May 2021; Accepted: 14 January 2022;

Published online: 03 February 2022

\section{References}

1. Vakkilainen, S., Taskinen, M. \& Makitie, O. Immunodeficiency in cartilagehair hypoplasia: Pathogenesis, clinical course and management. Scand. J. Immunol. 92, e12913 (2020).

2. de la Fuente, M. A. et al. Reduced thymic output, cell cycle abnormalities, and increased apoptosis of T lymphocytes in patients with cartilage-hair hypoplasia. J. Allergy Clin. Immunol. 128, 139-146 (2011).

3. Kostjukovits, S. et al. Analysis of clinical and immunologic phenotype in a large cohort of children and adults with cartilage-hair hypoplasia. J. Allergy Clin. Immunol. 140, 612-614 e615 (2017).

4. Obst, R. The Timing of T Cell Priming and Cycling. Front Immunol. 6, 563 (2015).

5. Smith-Garvin, J. E., Koretzky, G. A. \& Jordan, M. S. T cell activation. Annu Rev. Immunol. 27, 591-619 (2009).

6. Tan, T. C. J. et al. Suboptimal T-cell receptor signaling compromises protein translation, ribosome biogenesis, and proliferation of mouse CD8 T cells. Proc. Natl Acad. Sci. USA 114, E6117-E6126 (2017).

7. Howden, A. J. M. et al. Quantitative analysis of T cell proteomes and environmental sensors during $\mathrm{T}$ cell differentiation. Nat. Immunol. 20, 1542-1554 (2019).

8. Aubert M., O’Donohue M. F., Lebaron S., Gleizes P. E. Pre-Ribosomal RNA Processing in Human Cells: From Mechanisms to Congenital Diseases. Biomolecules 8, 123 (2018).

9. Tafforeau, L. et al. The Complexity of Human Ribosome Biogenesis Revealed by Systematic Nucleolar Screening of Pre-rRNA Processing Factors. Mol. Cell 51, 539-551 (2013).

10. Henras, A. K., Plisson-Chastang, C., Humbert, O., Romeo, Y. \& Henry, Y. Synthesis, Function, and Heterogeneity of snoRNA-Guided Posttranscriptional Nucleoside Modifications in Eukaryotic Ribosomal RNAs. Enzymes 41, 169-213 (2017).

11. Tollervey, D. Genetic and biochemical analyses of yeast RNase MRP. Mol. Biol. Rep. 22, 75-79 (1995).

12. Mattijssen, S., Welting, T. J. \& Pruijn, G. J. RNase MRP and disease. Wiley Interdiscip. Rev. RNA 1, 102-116 (2010).

13. Chang, D. D., Clayton, D. A. \& Mouse RNAase, M. R. P. RNA is encoded by a nuclear gene and contains a decamer sequence complemetary to a conserved region of mitochondrial RNA substrate. Cell 56, 131-139 (1989).

14. Lygerou, Z., Allmang, C., Tollervey, D. \& Séraphin, B. Accurate processing of a eukaryotic pre-rRNA by RNase MRP in vitro. Science 272, 268-270 (1996).

15. Lygerou, Z., Mitchell, P., Petfalski, E., Seraphin, B. \& Tollervey, D. The POP1 gene encodes a protein component common to the RNase MRP and RNase P ribonucleoproteins. Genes Dev. 8, 1423-1433 (1994).

16. Mitchell, P., Petfalski, E. \& Tollervey, D. The $3^{\prime}$-end of yeast $5.8 \mathrm{~S}$ rRNA is generated by an exonuclease processing mechanism. Genes Dev. 10, 502-513 (1996).

17. Henry, Y. et al. The $5^{\prime}$ end of yeast $5.8 \mathrm{~S}$ rRNA is generated by exonucleases from an upstream cleavage site. Embo J. 13, 2452-2463 (1994).

18. Henras, A. K., Plisson-Chastang, C., O’Donohue, M. F., Chakraborty, A. \& Gleizes, P. E. An overview of pre-ribosomal RNA processing in eukaryotes. Wiley Interdiscip. Rev. RNA 6, 225-242 (2015).

19. Woolford, J. L. Jr \& Baserga, S. J. Ribosome biogenesis in the yeast Saccharomyces cerevisiae. Genetics 195, 643-681 (2013).

20. Thiel, C. T. et al. Severely incapacitating mutations in patients with extreme short stature identify RNA-processing endoribonuclease RMRP as an essential cell growth regulator. Am. J. Hum. Genet 77, 795-806 (2005).
21. Goldfarb, K. C. \& Cech, T. R. Targeted CRISPR disruption reveals a role for RNase MRP RNA in human preribosomal RNA processing. Genes Dev. 31, 59-71 (2017).

22. Sloan, K. E. et al. Both endonucleolytic and exonucleolytic cleavage mediate ITS1 removal during human ribosomal RNA processing. J. Cell Biol. 200, 577-588 (2013).

23. Warren, A. J. Molecular basis of the human ribosomopathy ShwachmanDiamond syndrome. Adv. Biol. Regul. 67, 109-127 (2018).

24. Warren A. J. Chapter 17-Ribosomopathies and the Quality Control of Ribosome Assembly. In Congenital and Acquired Bone Marrow Failure (eds Aljurf M. D., Gluckman E., Dufour C.). Elsevier (2017).

25. Mills E. W., Green R. Ribosomopathies: There's strength in numbers. Science 358, eaan2755 (2017).

26. Farley-Barnes, K. I., Ogawa, L. M. \& Baserga, S. J. Ribosomopathies: Old Concepts, New Controversies. Trends Genet.: TIG 35, 754-767 (2019).

27. Narla, A. \& Ebert, B. L. Ribosomopathies: human disorders of ribosome dysfunction. Blood 115, 3196-3205 (2010).

28. Hsiau T., et al. Inference of CRISPR Edits from Sanger Trace Data. bioRxiv, 251082 (2019).

29. Mullineux, S. T. \& Lafontaine, D. L. Mapping the cleavage sites on mammalian pre-rRNAs: where do we stand? Biochimie 94, 1521-1532 (2012).

30. Wang, M., Anikin, L. \& Pestov, D. G. Two orthogonal cleavages separate subunit RNAs in mouse ribosome biogenesis. Nucleic Acids Res 42, 11180-11191 (2014)

31. Vakkilainen, $\mathrm{S}$. et al. The human long non-coding RNA gene RMRP has pleiotropic effects and regulates cell-cycle progression at G2. Sci. Rep. 9, 13758 (2019).

32. Koeffler, H. P. \& Golde, D. W. Human myeloid leukemia cell lines: a review. Blood 56, 344-350 (1980).

33. Adli, M. The CRISPR tool kit for genome editing and beyond. Nat. Commun. 9, 1911 (2018).

34. Metzl-Raz E. et al. Principles of cellular resource allocation revealed by condition-dependent proteome profiling. Elife 6, (2017).

35. Jarzebowski, L. et al. Mouse adult hematopoietic stem cells actively synthesize ribosomal RNA. RNA 24, 1803-1812 (2018).

36. Schroeder, A. et al. The RIN: an RNA integrity number for assigning integrity values to RNA measurements. BMC Mol. Biol. 7, 3 (2006).

37. Shchepachev, V. et al. Defining the RNA interactome by total RNA-associated protein purification. Mol. Syst. Biol. 15, e8689 (2019).

38. Ong, S. E. et al. Stable isotope labeling by amino acids in cell culture, SILAC, as a simple and accurate approach to expression proteomics. Mol. Cell Proteom. 1, 376-386 (2002).

39. Greber, B. J. \& Ban, N. Structure and Function of the Mitochondrial Ribosome. Annu Rev. Biochem 85, 103-132 (2016).

40. Esakova, O., Perederina, A., Quan, C., Schmitt, M. E. \& Krasilnikov, A. S. Footprinting analysis demonstrates extensive similarity between eukaryotic RNase P and RNase MRP holoenzymes. RNA 14, 1558-1567 (2008).

41. Esakova, O. \& Krasilnikov, A. S. Of proteins and RNA: the RNase P/MRP family. RNA 16, 1725-1747 (2010).

42. Glazov, E. A. et al. Whole-exome re-sequencing in a family quartet identifies POP1 mutations as the cause of a novel skeletal dysplasia. PLoS Genet 7, e1002027 (2011).

43. Elalaoui, S. C. et al. Further evidence of POP1 mutations as the cause of anauxetic dysplasia. Am. J. Med Genet A 170, 2462-2465 (2016).

44. Barraza-Garcia, J. et al. Broadening the phenotypic spectrum of POP1-skeletal dysplasias: identification of POP1 mutations in a mild and severe skeletal dysplasia. Clin. Genet 92, 91-98 (2017).

45. Perederina, A. et al. Cryo-EM structure of catalytic ribonucleoprotein complex RNase MRP. Nat. Commun. 11, 3474 (2020).

46. Lan, P. et al. Structural insight into precursor ribosomal RNA processing by ribonuclease MRP. Science 369, 656-663 (2020).

47. Granneman, S., Kudla, G., Petfalski, E. \& Tollervey, D. Identification of protein binding sites on U3 snoRNA and pre-rRNA by UV cross-linking and high-throughput analysis of cDNAs. Proc. Natl Acad. Sci. USA 106, 9613-9618 (2009)

48. Hunziker, M. et al. UtpA and UtpB chaperone nascent pre-ribosomal RNA and U3 snoRNA to initiate eukaryotic ribosome assembly. Nat. Comm. 7, 12090-12090 (2016).

49. Smola, M. J., Calabrese, J. M. \& Weeks, K. M. Detection of RNA-Protein Interactions in Living Cells with SHAPE. Biochemistry 54, 6867-6875 (2015).

50. Busan, S. \& Weeks, K. M. Accurate detection of chemical modifications in RNA by mutational profiling (MaP) with ShapeMapper 2. RNA 24, 143-148 (2018).

51. Smola, M. J. \& Weeks, K. M. In-cell RNA structure probing with SHAPEMaP. Nat. Protoc. 13, 1181-1195 (2018).

52. Khajuria, R. K. et al. Ribosome Levels Selectively Regulate Translation and Lineage Commitment in Human Hematopoiesis. Cell 173, 90-103 e119 (2018). 
53. Steinbusch, M. M. F. et al. Expression of RMRP RNA is regulated in chondrocyte hypertrophy and determines chondrogenic differentiation. Sci. Rep. 7, 6440 (2017).

54. Schmitt, M. E., Bennett, J. L., Dairaghi, D. J. \& Clayton, D. A. Secondary structure of RNase MRP RNA as predicted by phylogenetic comparison. FASEB J. 7, 208-213 (1993).

55. Chirnomas, S. D. \& Kupfer, G. M. The inherited bone marrow failure syndromes. Pediatr. Clin. North Am. 60, 1291-1310 (2013).

56. Brachmann, C. B. et al. Designer deletion strains derived from Saccharomyces cerevisiae S288C: a useful set of strains and plasmids for PCR-mediated gene disruption and other applications. Yeast 14, 115-132 (1998).

57. Gietz, R. D. \& Woods, R. A. Transformation of yeast by lithium acetate/singlestranded carrier DNA/polyethylene glycol method. Methods Enzymol. 350, 87-96 (2002).

58. Rouquette, J., Choesmel, V. \& Gleizes, P. E. Nuclear export and cytoplasmic processing of precursors to the $40 \mathrm{~S}$ ribosomal subunits in mammalian cells. EMBO J. 24, 2862-2872 (2005)

59. Mustoe A. M., Lama N. N., Irving P. S., Olson S. W., Weeks K. M. RNA basepairing complexity in living cells visualized by correlated chemical probing. Proc. Natl. Acad. Sci. 116, 24574-24582 (2019).

60. Smola, M. J., Rice, G. M., Busan, S., Siegfried, N. A. \& Weeks, K. M. Selective $2^{\prime}$-hydroxyl acylation analyzed by primer extension and mutational profiling (SHAPE-MaP) for direct, versatile and accurate RNA structure analysis. Nat. Protoc. 10, 1643-1669 (2015).

61. McKellar S. W. et al. Monitoring Protein-RNA Interaction Dynamics in vivo at High Temporal Resolution using chiCRAC. J. Vis. Exp. 19, e61027 (2020).

62. Bresson, S. et al. Stress-Induced Translation Inhibition through Rapid Displacement of Scanning Initiation Factors. Mol. Cell 80, 470-484 e478 (2020).

63. Bayne R., Bresson S., Tollervey D., Wallace E. CRAC Analysis in Budding Yeast with HTP Tagged Proteins. (2020).

64. Webb, S., Hector, R. D., Kudla, G. \& Granneman, S. PAR-CLIP data indicate that Nrd1-Nab3-dependent transcription termination regulates expression of hundreds of protein coding genes in yeast. Genome Biol. 15, R8 (2014).

65. Dodt, M., Roehr, J. T., Ahmed, R. \& Dieterich, C. FLEXBAR-Flexible Barcode and Adapter Processing for Next-Generation Sequencing Platforms. Biol. (Basel) 1, 895-905 (2012).

\section{Acknowledgements}

We thank Prof. Sophie Hambleton from Newcastle University for providing patient and control fibroblasts, sourced from the Great North Biobank (REC number 16-NE-0002). We also thank Richard Clark, Martin Waterfall and Fiona Rossi for technical assistance, and Sarah Walmsley and Edward Wallace for helpful discussions. This work was supported by Wellcome through an Edinburgh Clinical Academic Track fellowship to NR (213011), a Wellcome Principal Research Fellowship to DT (077248) and Wellcome Trust Investigator Award to RZ (WT205014/Z/16/Z). Work in the Wellcome Centre for Cell Biology is supported by a Centre Core grant (203149).

\section{Author contributions}

N.R., R.Z., and D.T. conceived the project and wrote the manuscript. N.R., V.S., D.W., T.T., and C.S. performed experiments. N.R., V.S., D.W., T.T., A.H., R.Z., and D.T. designed experiments. N.R., V.S., C.S., and T.T. analyzed data. All authors edited and reviewed the manuscript.

\section{Competing interests}

The authors declare no competing interests.

\section{Additional information}

Supplementary information The online version contains supplementary material available at https://doi.org/10.1038/s41467-022-28295-8.

Correspondence and requests for materials should be addressed to David Tollervey.

Peer review information Nature Communications thanks the anonymous reviewer(s) for their contribution to the peer review of this work. Peer reviewer reports are available.

Reprints and permission information is available at http://www.nature.com/reprints

Publisher's note Springer Nature remains neutral with regard to jurisdictional claims in published maps and institutional affiliations.

(c) (i) Open Access This article is licensed under a Creative Commons Attribution 4.0 International License, which permits use, sharing, adaptation, distribution and reproduction in any medium or format, as long as you give appropriate credit to the original author(s) and the source, provide a link to the Creative Commons license, and indicate if changes were made. The images or other third party material in this article are included in the article's Creative Commons license, unless indicated otherwise in a credit line to the material. If material is not included in the article's Creative Commons license and your intended use is not permitted by statutory regulation or exceeds the permitted use, you will need to obtain permission directly from the copyright holder. To view a copy of this license, visit http://creativecommons.org/ licenses/by/4.0/.

(C) The Author(s) 2022 